\title{
Lesions of the Perirhinal and Parahippocampal Cortices in the Monkey Produce Long-lasting Memory Impairment in the Visual and Tactual Modalities
}

\author{
Wendy A. Suzuki, ${ }^{1,2}$ Stuart Zola-Morgan, ${ }^{1,3}$ Larry R. Squire, ${ }^{1,3}$ and David G. Amaral ${ }^{1,2}$ \\ ${ }^{1}$ Group in Neurosciences, University of California at San Diego, La Jolla, California 92093, ${ }^{2}$ The Salk Institute, San Diego, \\ California 92186, and ${ }^{3}$ Veterans Affairs Medical Center, San Diego, California 92161 and Department of Psychiatry, \\ University of California at San Diego, La Jolla, California 92093
}

\begin{abstract}
Compared to normal animals, monkeys with bilateral lesions of the perirhinal and parahippocampal cortices (PRPH lesion) were impaired on both a visual and a tactual version of the delayed nonmatching to sample task. In addition, the memory deficit was long-lasting, as indicated by the finding of a significant deficit when the visual version of the delayed nonmatching to sample task was readministered approximately 2 years after surgery. Animals with PRPH lesions performed normally on discrimination tasks in the visual and tactual modalities. Multimodal and long-lasting memory impairments are defining characteristics of human medial temporal lobe amnesia. Accordingly, these results demonstrate important parallels between the memory deficit associated with PRPH lesions and human medial temporal lobe amnesia. These data, taken together with previous findings, suggest that the perirhinal and parahippocampal cortices play an important role in memory function and that these cortical areas are critical components of the medial temporal lobe memory system.
\end{abstract}

[Key words: memory, hippocampus, amnesia, medial temporal lobe, delayed nonmatching to sample task, nonhuman primate]

It has been known since the 1950s, due initially to the study of the famous amnesic patient H.M., that the medial temporal lobe is essential for normal memory function (Scoville and Milner, 1957). In the monkey, bilateral damage to medial temporal lobe structures including the hippocampal formation (made up of the dentate gyrus, the hippocampus proper, the subicular complex, and the entorhinal cortex), amygdala, and adjacent perirhinal and parahippocampal cortices $\left(\mathrm{H}^{+} \mathrm{A}+\right.$ lesion) produces a severe memory impairment (Mishkin, 1978; Zola-Morgan and Squire, 1985) that resembles human amnesia in many ways (Squire and Zola-Morgan, 1991). For example, as in hu-

\footnotetext{
Received June 4, 1992; revised Nov. 23, 1992; accepted Dec. 9, 1992.

This work was supported by the Medical Research Service of the Department of Veterans Affairs, NIH Grants 19063 and 16980, the Office of Naval Research, and the McKnight Foundation. W.A.S. was supported by the Systems and Integrative Ncurobiology Training Grant GM08107-06, and by NIMH Predoctoral Fellowship MH10033-02. We thank Pablo Alvarez-Royo, Cecelia Leclair, and Melodee Strukelj for behavioral testing, Robert P. Clower and Janet Weber for surgical assistance, Mary Ann Lawrence for histological assistance, and Kris Trulock for photographic processing.

Correspondence should be addressed to Dr. Stuart Zola-Morgan, Department of Psychiatry, M-003, U.C.S.D. School of Medicine, La Jolla, CA 92093.

Copyright (C) 1993 Society for Neuroscience 0270-6474/93/132430-22\$05.00/0
}

man amnesia, the deficit associated with $\mathrm{H}^{+} \mathrm{A}^{+}$lesions in monkeys is multimodal (Murray and Mishkin, 1984) and long-lasting (Zola-Morgan and Squire, 1985). In addition, animals with $\mathrm{H}^{+} \mathrm{A}^{+}$lesions exhibit preserved short-term memory (Overman et al., 1990), intact skill-based memory, and intact habit-like forms of memory (Malamut et al., 1984; Zola-Morgan and Squire, 1984) in analogy to the preserved memory abilities of human amnesic patients (for reviews, see Squire and Zola-Morgan, 1991; Squire, 1992).

Although the importance of the medial temporal lobe for memory function has been known for some time, a critical issue for current research has been to determine the relative contributions of the individual structures within the medial temporal lobe. A large body of evidence in both monkeys and humans supports the idea that the hippocampal formation is important for memory function (Mahut et al., 1982; Zola-Morgan et al., 1986, 1989a; Squire et al., 1990; Victor and Agamanolis, 1990). The amygdala, however, does not appear to contribute to the same kind of memory (Zola-Morgan et al., 1989b; Squire and Zola-Morgan, 1991; Murray, 1992). An important recent finding has been that two additional medial temporal lobe structures, the perirhinal and parahippocampal cortices, also contribute to memory function (Horel et al., 1987; Zola-Morgan et al., 1989c; Meunier et al., 1990; Gaffan and Murray, 1992). In one study, a group of monkeys sustaining bilateral lesions limited to the perirhinal and parahippocampal cortices (referred to in the present article as the PRPH I group from Zola-Morgan et al., 1989c) exhibited a severe visual memory impairment on three tasks sensitive to medial temporal lobe amnesia. In order to examine further how closely the deficit following PRPH lesions resembles human medial temporal lobe amnesia, two major issues were addressed.

The first issue concerns whether the memory deficit exhibited by animals with PRPH lesions extends to more then one sensory modality. In the previous study, the PRPH I group was tested only in the visual modality. Yet, an important characteristic of human amnesia is that it is modality general. The second issue concerns whether or not the memory impairment associated with the PRPH lesion is enduring. In the previous study, because the PRPH I group was never retested on the earlier tasks, no estimate of the stability of the impairment was obtained. If the momory deficit cxhibitcd by the PRPH group is similar to the human amnesic syndrome, it should be long-lasting. In the present study, we evaluated the memory impairment in a group of monkeys that received conjoint bilateral lesions limited to the 
perirhinal and parahippocampal cortices (PRPH II group). To determine if the memory deficit extended to more than one modality, the PRPH II group and a normal control group were tested on several tasks in both the visual and tactual modalities. To determine if the memory deficit was long-lasting, the PRPH II group and the normal control group were tested on the visual version of the delayed nonmatching to sample (DNMS) task shortly after surgery and then again approximately 2 years later. In addition, the PRPH II group and the normal group were tested on two additional amnesia-sensitive tasks. Also, in order to examine discrimination learning in the visual and tactual modalities, the two groups were tested on a visual pattern discrimination task and a tactual discrimination task.

\section{Materials and Methods}

\section{Subjects}

Seven male cynomolgus monkeys (Macaca fascicularis) were used, all weighing between 3.7 and $4.5 \mathrm{~kg}$. Four monkeys received bilateral lesions of the perirhinal and parahippocampal cortices (PRPH II group). The remaining three monkeys comprised an unoperated control group (N group) and were tested concurrently with the PRPH II group. For purposes of clarity, the four monkeys in the previous study of the effects of PRPH lesions (Zola-Morgan et al., 1989c) will be referred to as the PRPH I group and the animals will be designated as animals PRPH 1, 2, 3, and 4. In the present study, the four monkeys in the PRPH II group will be designated as animals PRPH 5, 6, 7, and 8 .

\section{Surgery}

The surgical procedures used for the PRPH lesion have been described in detail elsewhere (Zola-Morgan et al., 1989c). Histological examination of the animals in the PRPH I group (Zola-Morgan et al., 1989c) revealed that the most anterior part of the perirhinal cortex at the level of the temporal pole (area 36pm of Insausti et al., 1987) was spared in all four animals (Fig. 3 of Zola-Morgan et al., 1989c). Therefore, in the PRPH II group, an attempt was made to extend the lesion rostrally and dorsally to include more of the temporal polar portion of the perirhinal cortex (Fig. 1C, A25.0 and A22.0) The intended boundaries for the lesion of the ventral part of perirhinal cortex (areas 35, 36r, and 36c of Insausti et al., 1987) and the boundaries for the lesion of the parahippocampal cortex (areas TH and TF) were the same as described in ZolaMorgan et al. (1989c).

\section{Tactual apparatus}

The Wisconsin General Test Apparatus (WGTA; Harlow and Bromer, 1938), which is typically used for testing monkeys on visual tasks, was also used to test monkeys in the tactual modality. An opaque barrier ( $72 \mathrm{~cm}$ long by $18 \mathrm{~cm}$ high) was inserted between the testing cage and the stimulus tray in order to block the monkeys' view of the objects. A rectangular platform ( $8 \mathrm{~cm}$ wide by $45.5 \mathrm{~cm}$ long by $7.5 \mathrm{~cm}$ high) with its long axis oriented parallel to the opaque barrier was secured to the stimulus tray of the WGTA approximately $1.5 \mathrm{~cm}$ in front of the opaque barrier. The platform contained three equally spaced round wells, 6.4 $\mathrm{cm}$ in diameter. The junk objects used in the tactual tasks were mounted on round disks that fit snugly into the wells. The objects mounted on the round disks could be locked into place manually by the experimenter. A pool of approximately 70 objects differing in shape, size, and texture was used for the tactual tasks. At the bottom of each of the wells was a smaller well $(1.5 \mathrm{~cm}$ in diameter) that held the raisin rewards. The opaque barrier, the platform, and the tactual objects were constructed so that monkeys could easily grasp objects that were presented on the other side of the opaque barrier but could not see the objects from any position in the testing box. Careful behavioral observation during pretraining and administration of the tactual tasks confirmed that the monkeys could not see the objects from any position in the testing box. For example, during testing, the monkeys did not attempt to peer over the opaque barrier before making a choice but simply reached over the barrier to grasp the objects. Moreover, even when the monkeys were performing at criterion level on the two tactual tasks, they were equally likcly to grasp the correct or incorrect object during their first contact with the objects.

\section{Behavioral testing}

A total of seven tasks were administered, five in the visual modality and two in the tactual modality as described below. Detailed descriptions of the five visual tasks have been published previously (ZolaMorgan and Squire, 1984, 1985; Zola-Morgan et al., 1989b). Administration of the first visual task was preceded by pretraining procedures for the visual tasks, and the two tactual tasks were directly preceded by tactual pretraining procedures. The pretraining sessions and behavioral tasks were administered in the order given below.

\section{Pretraining procedure for the visual tasks}

Monkeys were allowed 6-8 weeks of recovery after surgery before the start of pretraining for the visual tasks. Pretraining for the visual tasks consisted of four to six daily sessions in the WGTA where monkeys learned to obtain raisin rewards by displacing objects that covered any of three food wells located on a stimulus tray in front of the testing chamber. When the monkeys readily displaced objects presented over any of the three wells, testing began on the visual version of the delayed nonmatching to sample (DNMS) task.

\section{Visual trial-unique delayed nonmatching to sample with double-sample presentation}

The DNMS task is known to be sensitive to human amnesia (Squire et al., 1988) and to medial temporal lobe damage in the monkey (ZolaMorgan and Squire, 1986). The task was administered as described in Zola-Morgan and Squire (1984), with the following modifications. Instead of receiving a single presentation of the sample object over the central well, which is the standard way of administering the task, both the PRPH II group and the $\mathrm{N}$ group received two successive presentations of the sample object (double-sample presentation procedure; Aggleton and Mishkin, 1983). One of the two sample presentations was rewarded according to a pseudorandom schedule (Gellerman, 1933). This modification of the testing procedure was adopted in response to difficulties encountered in an earlier study of the effects of PRPH lesions (PRPH I group; Zola-Morgan et al., 1989c). In that study, only one of the four animals in the PRPH I group (PRPH 1) was able to learn the basic task with the standard single-sample presentation procedure. Two of the remaining three animals were able to learn the task to criterion level of performance using the double-sample presentation procedure. The fourth animal did not reach criterion after 2000 trials, and training was discontinued. Because the normal control animals in that study did not receive double-sample presentation at any time during the task, it was difficult to compare directly the performance of the two groups. Therefore, in the present study, both the PRPH II group and the normal group were given double-sample presentation throughout the task. Training was discontinucd if animals did not reach criterion level performance (an average of $90 \%$ correct on 5 consecutive days of testing) within 2000 trials.

As in the conventional administration of this task, the second sample presentation was followed by the choice phase where the sample object and a novel object were presented over the lateral wells of the WGTA. The monkeys learned to displace the novel object to receive a raisin reward. The correct stimulus object appeared over the left or right food well in a Gellerman (1933) sequence, and a raisin reward was always concealed under each correct object. When the animal reached a criterion of 90 correct responses in five consecutive test sessions (100 trials) with a short 8 sec delay between the sample presentation and the choice phase (basic task), the delay interval was sequentially increased to 15 $\mathrm{sec}, 60 \mathrm{sec}$, and $10 \mathrm{~min}$. Both the PRPH II group and the $\mathrm{N}$ group received the double-sample presentation procedure during the delay portion of the task. One hundred trials were given at the 15 and $60 \mathrm{sec}$ delays; 50 trials were given at the 10 min delay. Due to a testing error, animal PRPH 6 received 25 trials instead of 50 trials at the 10 min delay interval.

\section{Pattern discrimination}

Monkeys were tested on two separate two-dimensional pattern discrimination tasks. In the first task, monkeys learned to discriminate a plus sign from a square, and in the second task they learned to discriminate an $\mathrm{N}$ from a W. The correct pattern of the pair appcarcd over the left or right food well in a Gellerman (1933) sequence, and a raisin reward 

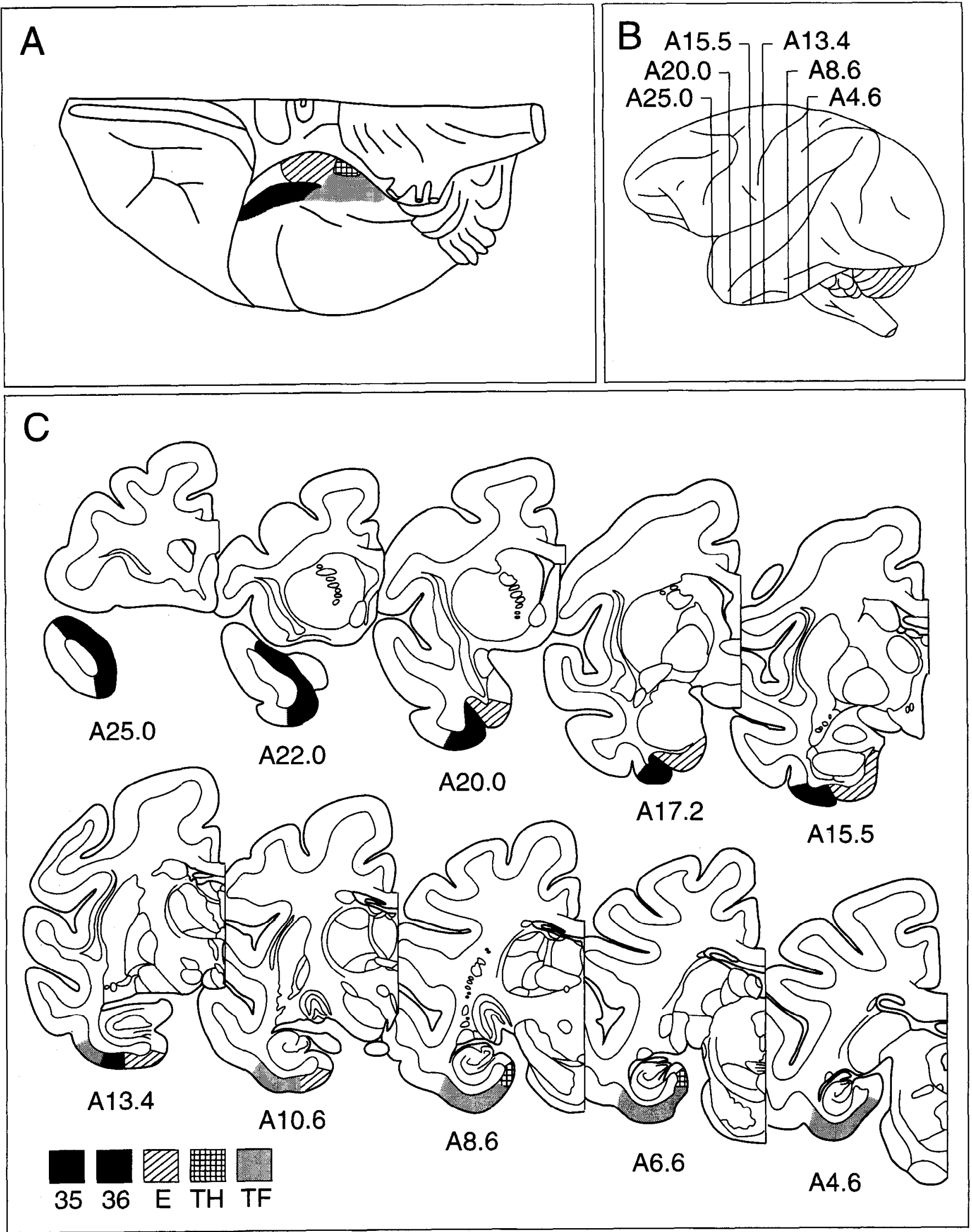
was always under the correct pattern. Training continued until animals achieved a learning criterion of $90 \%$ correct performance or better on 2 consecutive days. Thirty trials per day were administered for both pattern discrimination problems. However, the three animals in the $\mathrm{N}$ group received 20 trials per day for the first 260 trials of the first pattern discrimination problem (plus vs square). For the remainder of the training on the first pattern discrimination problem as well as for the second pattern discrimination problem, the animals in the $\mathrm{N}$ group received 30 trials per day.

\section{Delayed retention of object discrimination}

Monkeys learned three separate two-choice object discrimination tasks. Each discrimination pair consisted of distinctive objects that could be learned by normal monkeys in a single session. Each discrimination task was administered for two daily sessions of 20 trials each. Then, on the fourth day, an additional session of 20 trials was given. The correct stimulus object appeared over the left or right food well in a Gellerman (1933) sequence, and a raisin reward was always concealed within each correct object.

\section{Pretraining procedure for the tactual tasks}

Pretraining for the tactual tasks was administered in four phases. During the first three pretraining phases, a single tactual object was used and was always rewarded. During phase 4 , a pair of tactually distinct objects were used and one of these objects was always rewarded.

Phase 1. In phase 1, the platform, but not the opaque barrier, was used. The animals learned to displace an object and retrieve a reward when the object was placed randomly in one of the three object wells. Initially, the object was not locked into the object well and could easily be removed. When the animals readily displaced the unlocked object from the well, the object was then locked into place, and the animals were required to tug on the object three times before it was released by the experimenter. This procedure was continued throughout the rest of the pretraining procedure as well as during the administration of both tactual tasks. Pilot experiments showed that if monkeys were allowed to displace unlocked objects, they would quickly knock the objects out of the wells while searching for the reward without examining the objects tactually. Thus, the procedure of requiring the animals to tug on the object a fixed number of times helped ensure that they all received equal tactual exposure to the objects. During this phase of pretraining, a tone lasting approximately $1 \mathrm{sec}$, generated from a mini-electronic synthesizer, was presented immediately after the rewarded object was displaced to alert the animal to the presence of a reward. The tone was used throughout tactual pretraining and throughout the two tactual tasks. During the tactual tasks, the tone was always presented immediately after a correct object was displaced. Phase 1 typically required one or two testing sessions. In this phase and all subsequent tactual pretraining phases, there were no differences in the amount of time required to complete the tactual pretraining phases for the lesioned animals compared to the normal animals.

Phase 2. In the next phase, a transparent barrier was inserted into the WGTA between the testing cage and the stimulus tray. Thus, the animals could still see the object and learned to reach over the transparent barrier to displace the object. Again, they were required to tug three times before the object was released, and the tone was presented each time the object was successfully displaced. This phase required between two and four testing sessions.

Phase 3. In this phase, the animal's view of the objects was gradually decreased by attaching increasingly high opaque panels that covered the transparent barrier. At various times during this phase, the monkeys stopped performing the task, and their view of the objects had to be increased in order to encourage them to work again. Gradually, the animals learned to displace the object and retrieve the raisin rewards while reaching over a barrier that completely blocked visual access. This phase required 6-12 training sessions.

Phase 4. Pilot studies showed that if animals were tested on the twochoice tactual discrimination task (see below) immediately after phase 3 , they would reach over the opaque barrier and displace the first object they encountered without ever comparing that object with the second object. Accordingly, in order to encourage the animals to compare two adjacent objects on the other side of an opaque barrier, a fourth phase of pretraining was added. In this phase the animals learned to perform an easy visual object discrimination while reaching over the transparent barrier. All animals were trained using the same two objects. As the animals learned the visual object discrimination, the view of the objects was again gradually decreased by attaching the opaque panels onto the transparent barrier. When the animals could perform this object discrimination tactually to a criterion of $80-90 \%$ correct, training on the tactual discrimination tasks began. Phase 4 of tactual pretraining required approximately 10 training sessions.

\section{Tactual discrimination}

All animals were tested sequentially on four two-choice, tactual object discrimination problems. Each discrimination consisted of a pair of tactual objects that could be learned in an average of 40 trials. The objects were always presented over the two lateral object wells in the platform and the correct object of the pair appeared over the left or right object well in a Gellerman (1933) sequence. A raisin reward was always concealed under the correct object. As described above, a correct choice was always followed by a tone. Monkeys received 20 trials per day on each discrimination problem with an intertrial interval of 15 sec until they reached a criterion of $90 \%$ correct performance or better averaged across 2 consecutive days of testing.

\section{Tactual delayed nonmatching to sample with single-sample presentation}

Monkeys first reached over the opaque barrier and displaced a rewarded sample object locked into the central well. As described above, the monkeys were required to tug three times on the object before the object was released. Displacement of the sample object was immediately followed by a tone. An opaque door was then lowered in order to block the monkey's access to the central platform. After an $8 \mathrm{sec}$ delay, the opaque door was raised and monkeys could reach over and tactually examine both the sample object and a novel object that covered the two lateral object wells. The monkeys were required to displace the novel object to receive the raisin reward. Only displacement of the correct object was followed immediately by a tone. The correct object appeared over the left or the right object well in a Gellerman (1933) sequence. Twenty trials were presented daily with an intertrial interval of $20 \mathrm{sec}$. Each trial of a given session used a new pair of tactual objects selected from a collection of approximately 70 junk objects. After reaching the learning criterion of 90 correct choices in 100 trials, monkeys were tested with longer delays of $15 \mathrm{sec}(20 \mathrm{trials} / \mathrm{d}), 30 \mathrm{sec}(20 \mathrm{trials} /$ d), $60 \mathrm{sec}(20 \mathrm{trials} / \mathrm{d}), 2 \mathrm{~min}(10 \mathrm{trials} / \mathrm{d})$, and $10 \mathrm{~min}(5 \mathrm{trials} / \mathrm{d})$. One hundred trials were given at the $15 \mathrm{sec}, 30 \mathrm{sec}, 60 \mathrm{sec}$, and 2 min delay intervals, and 50 trials were given at the 10 min delay interval.

\section{Retest of visual delayed nonmatching to sample with double- sample presentation}

Approximately 2 years after surgery, all animals were retested on the visual version of the delayed nonmatching to sample task using the same double-sample presentation procedure described above.

Figure 1. A, Line drawing of the ventral surface of the right side of the brain of $M$. fascicularis. The locations of the perirhinal cortex (areas 35 and 36), entorhinal cortex $(E)$, and parahippocampal cortex (areas TH and TF) are indicated by different shading patterns (see legend in $C$ ). Area 35 of the perirhinal cortex is not visible in this view (see $C$ ). $B$, Line drawing of the lateral surface of the $M$. fascicularis monkey brain adapted from the atlas of Szabo and Cowan (1984). The rostrocaudal positions of the coronal sections illustrated in $C$ are indicated. $C$, Line drawings of representative coronal sections through the temporal lobe of $M$. fascicularis adapted from the atlas of Szabo and Cowan (1984). The sections are arranged from rostral $(A 25.0)$ to caudal $(A 4.6)$, and the rostrocaudal position of each section is indicated. The designations $A 25.0, A 22.0$, and so on, specify distances anterior $(A)$ from the intra-aural line. The boundaries of areas $35,36, T H, T F$, and the cntorhinal cortex $(E)$ are indicated by different shading patterns (see legend at lower left). 


\section{Concurrent discrimination}

Eight pairs of junk objects were used. The eight pairs of objects were presented in an intermingled fashion across trials within a test session so that all eight discriminations were learned concurrently. On each trial one pair of objects was presented over the lateral food wells, and during the course of each daily testing session of 40 trials, every pair was presented five times. Within a pair of objects, the same stimulus was consistently rewarded and the position of the correct object was determined by a Gellerman (1933) sequence. Testing continued until a learning criterion of 39 correct responses in 40 consecutive trials was achieved during one test session.

\section{Retrograde and anterograde tracer studies}

At the conclusion of all behavioral testing, injections of retrograde and anterograde tracers were made in all four of the animals in the PRPH II group. The surgical procedures for the tracer injections have been described in detail elsewhere (Insausti et al., 1987). In all cases, the coordinates for placement of the injections were derived from magnetic resonance images of the monkey's brain (Alvarez-Royo et al., 1991). In animals PRPH 6, PRPH 7, and PRPH 8, injections of $500 \mathrm{nl}$ of $2.0 \%$ diamidino yellow and $500 \mathrm{nl}$ of $3 \%$ fast blue were placed at two different rostrocaudal levels of the entorhinal cortex on one side. In these three animals, an injection of $100 \mathrm{nl}$ of a mixture of ${ }^{3} \mathrm{H}$-proline and ${ }^{3} \mathrm{H}$ leucine was also placed in the entorhinal cortex on the contralateral side. The postinjection survival time for these animals was $14 \mathrm{~d}$. Animal PRPH 6 dicd shortly after surgery, and therefore no anatomical information other than routine histology was available for this animal. Animal PRPH 5 died during surgery and in order to obtain some neuroanatomical information from this animal, we employed the anterograde tracer 1,1'-dioctodecyl-3,3,3,3'-tetramethylindocarbocyanine perchlorate (DiI). Following transcardial perfusion of fixatives (see below), crystals of DiI were placed at three different rostrocaudal positions within the entorhinal cortex on the right side of the brain. The brain was stored in a $4 \%$ paraformaldehyde solution in $0.1 \mathrm{~m}$ phosphate buffer at room temperature in the dark for 5 months before the start of histological processing.

\section{Histological processing}

Following deep anesthesia and loss of the corneal reflex, the animals were killed by transcardial perfusion of fixatives. Animals PRPH 7 and PRPH 8 were perfused with a solution of $1 \%$ paraformaldehyde in 0.1 M phosphate buffer followed by $4 \%$ paraformaldehyde in the same buffer and finally a $5 \%$ sucrose solution. Animal PRPH 6 was perfused with $0.9 \%$ sodium chloride solution followed by a $4 \%$ paraformaldehyde solution in $0.1 \mathrm{M}$ phosphate buffer. Animal PRPH 5 was perfused with a $0.9 \%$ sodium chloride solution followed by a $10 \%$ formalin solution in $0.1 \mathrm{M}$ phosphate buffer. All brains were cryoprotected in glycerol solutions and sectioned in the coronal plane on a freezing microtome. For animals PRPH 6, PRPH 7, and PRPH 8, sections were cut at 30 $\mu \mathrm{m}$, and every tenth section was mounted and stained with thionin to assess the extent of the lesions. For animals PRPH 7 and PRPH 8, a second series of sections was mounted and the distribution of retrogradely labeled cells was analyzed with a Leitz Dialux 20 microscope with fluorescence illumination. The distribution of labeled cells was plotted using a computer-aided digitizing system. A third series of mounted sections was processed for autoradiographic analysis. Finally, for animal PRPH 5, sections were cut at $30 \mu \mathrm{m}$, and every eighth section was mounted and stained for thionin to assess the extent of the lesions. A second series of sections from this animal was mounted, and the distribution of DiI-labeled axons was examined and plotted as described above.

\section{Construction of two-dimensional unfolded maps}

In order to construct each unfolded map, line drawings were made from a series of Nissl-stained sections (either a $1 / 16$ or a $1 / 20$ series cut at $30 \mu \mathrm{m}$ ) at a magnification of $13 \times$ with a Nikon stereomicroscope. The boundaries of the major cortical areas were then microscopically determined and marked onto the line drawings, and the sections were "unfolded" according to the procedure of Van Essen and Maunsell (1980). At rostral levels, all sections were aligned along the fundus of the rhinal sulcus, and at caudal levels sections were aligned along the border between the parahippocampal cortex and the subicular complex or area 29. The lateral boundary for these maps was the dorsal lip of the superior temporal sulcus. An average of 38 sections were used to construct each of the unfolded maps. In order to obtain an estimate of the amount of tissue damaged in the brains of the PRPH II animals, the surface area of the perirhinal cortex, parahippocampal cortex, TE, and TEO in a normal control brain matched for body weight, was compared to the corresponding areas in the animals of the PRPH II group. The difference in surface area between the brain of the normal control monkey and the brain of the monkey with the lesion was represented on the unfolded map as the area of damage. Due to the substantial variation in sulcal patterns and surface areas within the inferotemporal cortex of intact control animals, the unfolded maps are necessarily only estimates of the amount of surface area actually removed in the animals with lesions. A detailed description of the techniques used to construct the unfolded map of the temporal lobe will be given in a separate publication (W. A. Suzuki and D. G. Amaral, unpublished observations).

\section{Results}

\section{Histological results}

\section{Location of the perirhinal and parahippocampal cortices}

Before describing the extent of the lesions for each of the animals in the PRPH II group, we will briefly summarize the location and boundaries of these areas. The perirhinal and parahippocampal cortices form a band of cortex along the ventromedial surface of the temporal lobe (Fig. 1 $A$ ). The perirhinal cortex is the more rostral of the two areas and consists of a smaller, medially situated area $\mathbf{3 5}$ and a larger, laterally situated area 36 (Brodmann, 1909). The pcrirhinal cortex is locatcd latcral to the rhinal sulcus and follows the rhinal sulcus from its caudal boarder on the ventral surface of the brain, rostrally and dorsally to its termination at the frontotemporal junction (limen insula). At its most rostral and dorsal extent, the perirhinal cortex makes up much of what is typically referred to as the temporal pole or area TG. Throughout most of its rostrocaudal extent, the perirhinal cortex, is bounded laterally by area TE. At its most caudal end, the perirhinal cortex is bounded laterally by the rostral part of the parahippocampal cortex. The structures that form the medial border of the perirhinal cortex vary at different rostrocaudal levels. Rostrally, the medial border is formed by the piriform and periamygdaloid cortices. At caudal levels, the perirhinal cortex is bordered medially by the entorhinal cortex. The caudal boundary of the perirhinal cortex is formed by the rostral parahippocampal cortex.

The parahippocampal cortex is located just caudal to the entorhinal and perirhinal cortices and is comprised of a medially situated area TH and a larger, laterally situated area TF (von Bonin and Bailey, 1947). Through its rostrocaudal extent, the parahippocampal cortex is bounded laterally, first by the caudal part of area TE and then by area TEO. At the most rostral levels of the parahippocampal cortex, its medial border is formed by the caudal part of the entorhinal cortex. However, through most of its rostrocaudal extent, the medial border of the parahippocampal cortex is formed by the subicular complex. Area OA (von Bonin and Bailey, 1947), also referred to as area V4 (Zeki, 1971), forms the caudal boundary of the parahippocampal cortex. A detailed cytoarchitectonic description of the subdivisions of the perirhinal and parahippocampal cortices will be given in a separate report (Suzuki and Amaral, unpublished observations).

Figure $1 C$ shows line drawings of representative coronal sections, through the rostrocaudal extent of the perirhinal and parahippocampal cortices of $M$. fascicularis. The locations of the perirhinal, parahippocampal, and entorhinal cortices are indi- 
cated. It should be noted that the lateral borders of area 36 of the perirhinal cortex and area TF of the parahippocampal cortex shown in Figure $1 C$ are situated somewhat lateral to the borders previously shown in Figure 1 of Zola-Morgan et al. (1989c). The inclusion of these lateral areas within the boundaries of the perirhinal and parahippocampal cortices was prompted by recent neuroanatomical data indicating that these areas of cortex exhibit many of the same connections and immunohistochemical characteristics as the more medially situated cortex (Suzuki and Amaral, unpublished observations). Thus, the lesions in the animals of the PRPH II group were evaluated using these modified criteria for identifying the borders of areas 36 and TF.

\section{Description of the lesions in the PRPH II group}

General observations. The extent of the removal of the perirhinal and parahippocampal cortices was similar in all four of the animals in the PRPH II group. In all cases, most of the perirhinal cortex caudal to the level of the periamygdaloid cortex was removed, while the polar portion of the perirhinal cortex (area $36 \mathrm{pm}$ ) was only minimally damaged. In all cases, the vast majority of area TF was removed. However, because the lesion did not extend far enough medially, much of area TH was spared. There was some variability in the amount of medial TE involved in the lesion. Whereas animals PRPH 6 and PRPH 7 sustained little or no direct damage of area TE, animals PRPH 5 and PRPH 8 sustained more TE damage.

The extent of the lesion in each case is plotted on representative coronal sections (Fig. 2). The rostrocaudal levels used to illustrate the lesions are the same as those used in Figure 1. Figure 3 shows two-dimensional unfolded maps of the right hemisphere including the entorhinal, perirhinal, and parahippocampal cortices along with the laterally adjacent areas TE and TEO. A representative normal brain, and the brains of the four animals in the PRPH II group are shown. The extent of the lesion in the four PRPH II animals is shown as a shaded area. The full rostrocaudal extent of the ablation in animal PRPH 7 is shown in a series of photomicrographs (Fig. 4). Because this animal had a lesion that most closely approximated the intended lesion, we begin by describing the lesion in this animal and then provide shorter, comparative descriptions of the lesions in the other animals in the PRPH II group.

PRPH 7. Rostrally, the lesion in animal PRPH 7 started at the level of the temporal pole as a small defect involving layers I and II near the ventromedial tip of the pole (A25.0). At the level of the periamygdaloid cortex (A22.0), the lesion expanded to encompass all layers of area 36. Rostral to the periamygdaloid cortex, however, much of the temporal polar portion of areas 35 and 36 was spared bilaterally. Caudal to the level of the periamygdaloid cortex, much of the perirhinal cortex was removed on both sides, although the most lateral aspect of area 36 was spared bilaterally. In this case, there was little or no direct damage to the entorhinal cortex on the right side. However, on the left, there was a small amount of direct damage to the most lateral part of the entorhinal cortex through its rostrocaudal extent. In all cases, the white matter subjacent to the lesion was examined. This white matter carries much of the afferent and efferent input of the entorhinal cortex with other neocortical areas such as the superior temporal gyrus, cingulate cortex, and insular cortex. In animal PRPH 7, the white matter was transected on the left side beginning at the mid-level of the amygdala (A17.2) and on the right side, beginning at the caudal amygdala (A15.5). The white matter remained fully transected throughout the rest of the caudal extent of the lesion. There was no direct damage to area TE lateral to the perirhinal cortex.

Continuing caudally, most of area TF was removed bilaterally. However, the most lateral part of area TF was spared. Area $\mathrm{TH}$ was spared on the right side but there was more direct damage to the rostral part of area $\mathrm{TH}$ on the left side. There was no direct damage to the hippocampus in this animal. There was also no involvement of the caudal part of area TE or area TEO lateral to the parahippocampal cortex. The lesion in animal PRPH 7 ended near the caudal border of area TF.

To summarize, the lesion in animal PRPH 7 removed much of the ventrally situated perirhinal cortex, although the most lateral portion of area 36 was spared bilaterally. The temporal polar portion of the perirhinal cortex was minimally damaged. Much of area TF was removed, although the most lateral part of area TF was also spared bilaterally. The rostral part of area $\mathrm{TH}$ was damaged only on the left side. The entorhinal cortex was only minimally damaged on the left side. There was essentially no direct involvement of area TE, area TEO, the hippocampus, or the amygdala. Finally, the white matter subjacent to the fundus of the rhinal sulcus was transected at the mid- to caudal levels of the amygdala and remained transected throughout the remaining rostrocaudal extent of the lesion.

$P R P H$ 6. The lesion of the perirhinal cortex in animal PRPH 6 was very similar to that of animal PRPH 7. Much of the perirhinal cortex was removed on both sides starting from the level of the rostral entorhinal cortex (A20.0). Similar to the lesion in animal PRPH 7, a small part of the lateral aspect of area 36 was spared bilaterally. The entorhinal cortex was completely spared on the right side, although its most lateral aspect was damaged on the left. The white matter subjacent to the rhinal sulcus on both sides was not fully transected until the level of the rostral hippocampus (A13.4). The lesion involved most of area TF bilaterally, although a portion of medial TF was spared on the right sidc. The most caudal part of arca TF was also spared bilaterally. Area TH was spared on both sides. There was minor direct damage to area TE for a short rostrocaudal extent on the left side, but area TE was completely intact on the right. Neither the amygdala nor the hippocampus was directly involved in the lesion.

$P R P H$ 5. In animal PRPH 5, the rostrocaudal extent of the damage to the perirhinal and parahippocampal cortex was very similar to that of animal PRPH 7. However, in this case, because the lesion extended farther laterally and involved part of the medial aspects of areas TE and TEO (Figs. 2, 3), the most lateral aspect of areas 36 and TF, which were partially spared in animal PRPH 7, were completely removed in animal PRPH 5. There was some direct damage to the medial aspect of area TE bilaterally throughout the level of the amygdala. There was little or no direct damage to the entorhinal cortex and no direct damage to the amygdala or hippocampus. On the left side, the white matter was transected beginning at the level of the caudal amygdala (A15.5). On the right side, most of the white matter was transected beginning at the level of the caudal amygdala; however, there appeared to be a small amount of intact white matter present until approximately the mid-level of the hippocampus (A6.6). Most of area TF was removed in this animal, but area TH was spared bilaterally. Through the level of the parahippocampal cortex, there was only slight involvement of areas TE and TEO on the right. On the left, these areas were more extensively damaged. 


\section{PRPH 5}
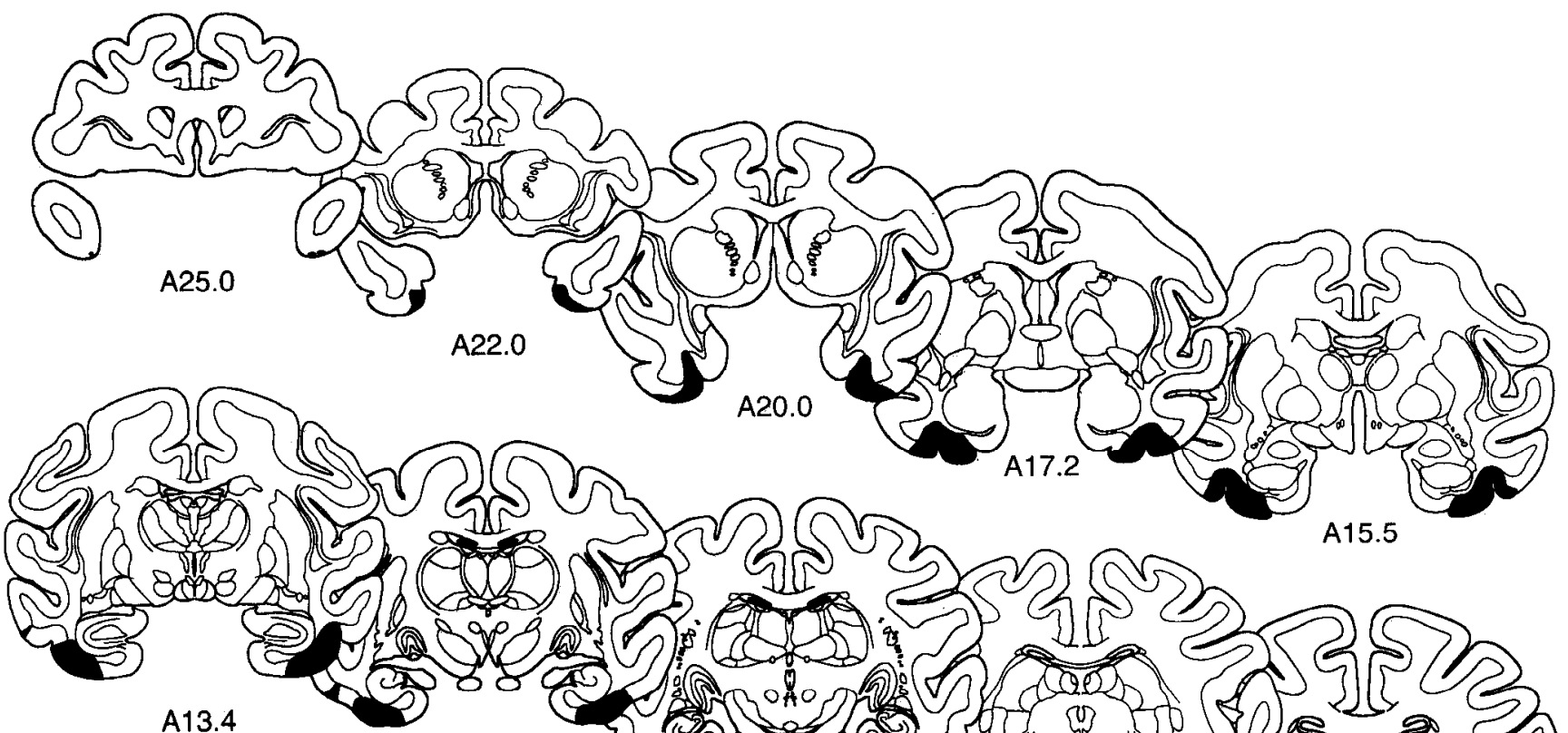

A13.4

A10.6

PRPH 6

A8.6

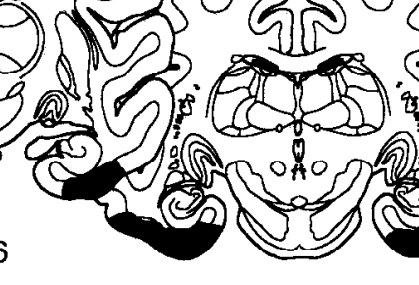

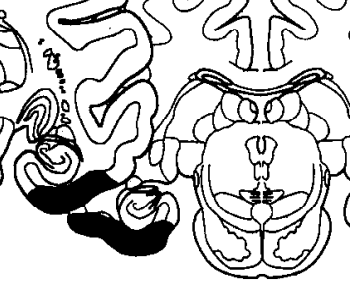

A6.6
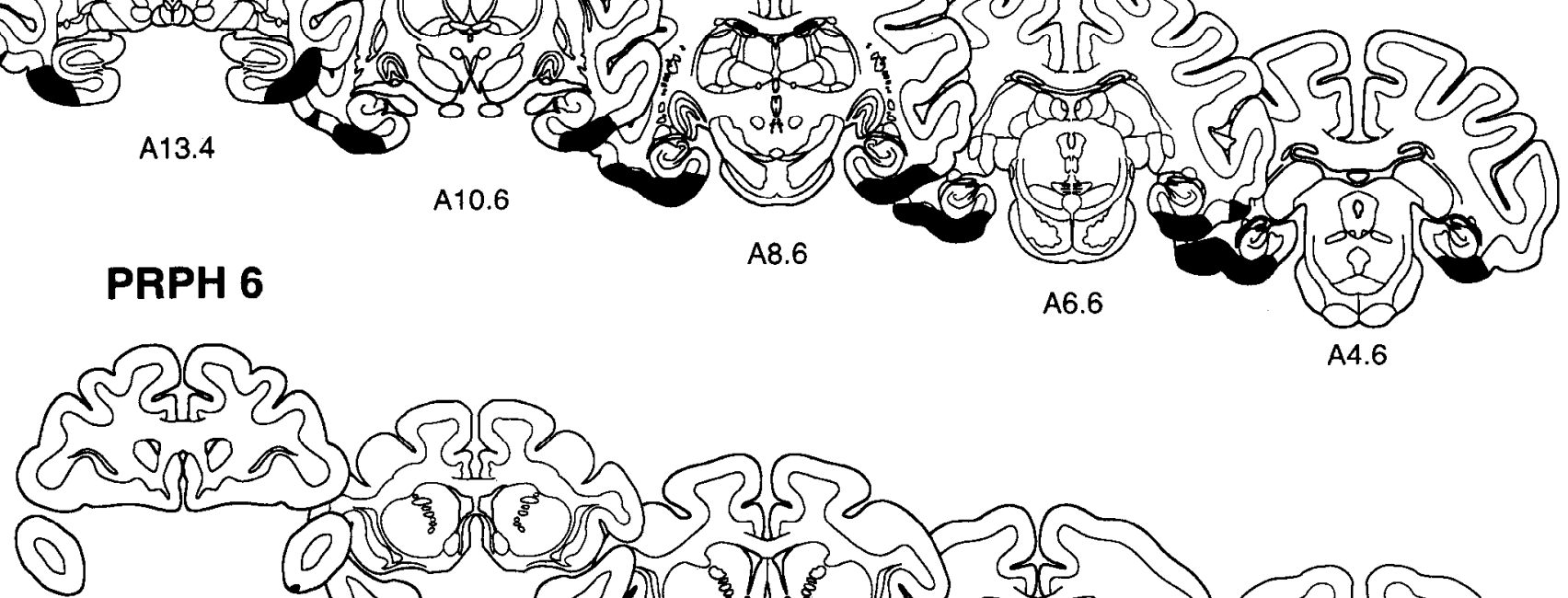

A25.0
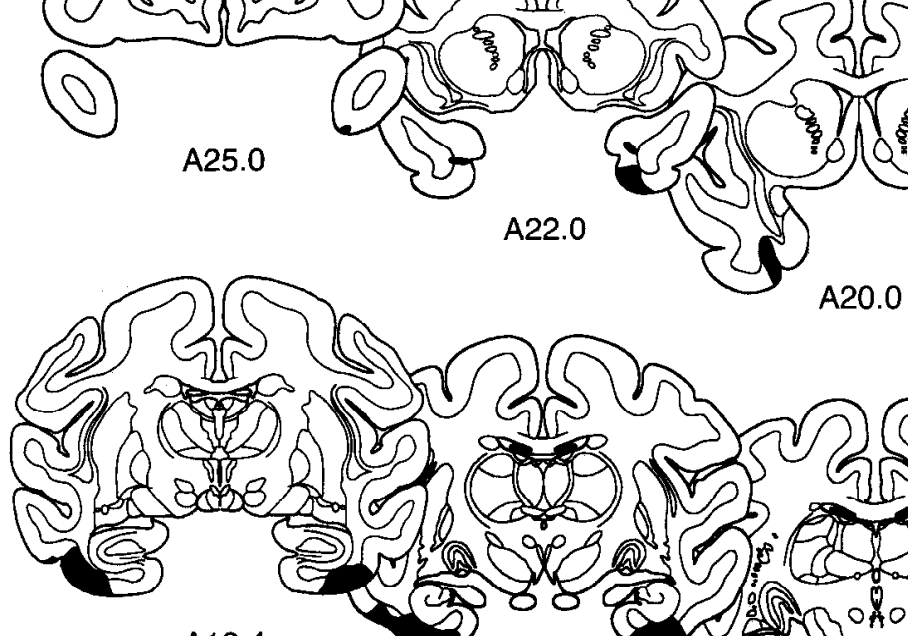

$$
\text { A10.6 }
$$

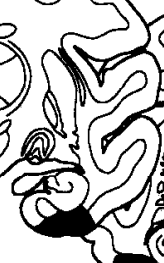

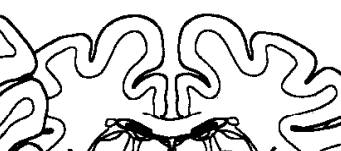

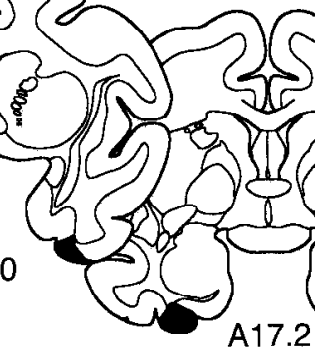

A17.2

A4.6

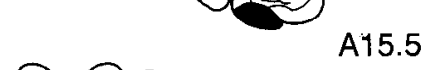

A15.5

A6.6

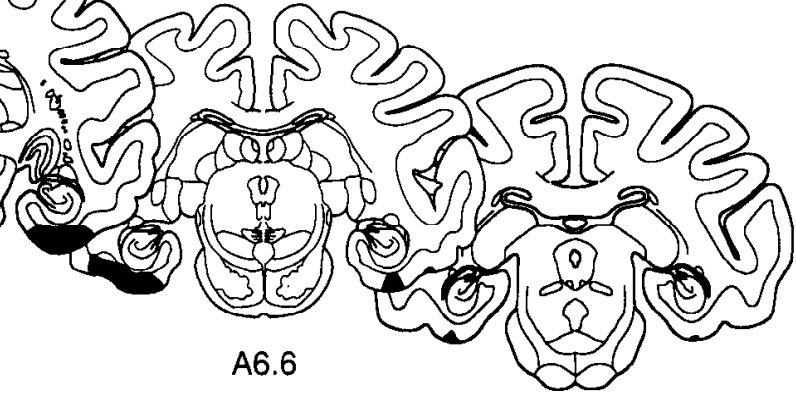

A4.6

Figure 2. The extent of the lesions of the perirhinal and parahippocampal cortex in each of the four experimental animals in the PRPH II group $(P R P H 5-8)$ is plotted on representative coronal sections redrawn from the atlas of Szabo and Cowan (1984). In each case, the area of the lesion is indicated in black. The rostrocaudal level is indicated below each section. 


\section{PRPH 7}

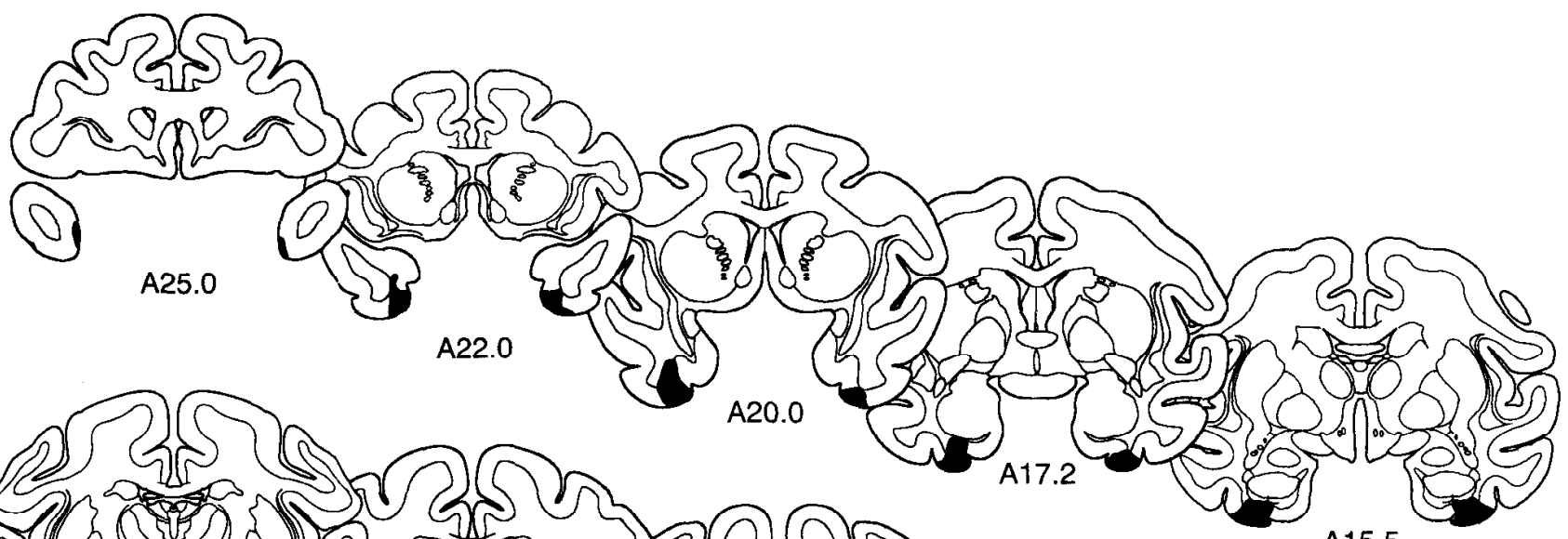

a)

(5)

A13.4

A10.6

PRPH 8

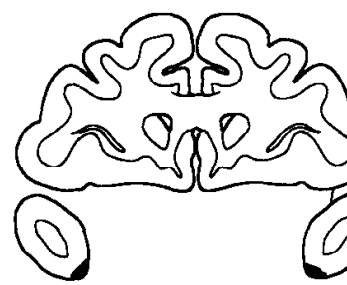

A25.0

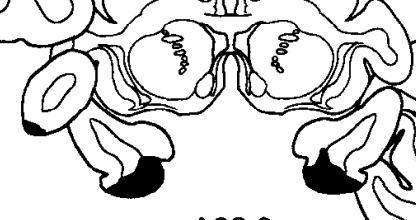

A22.0

A8.6

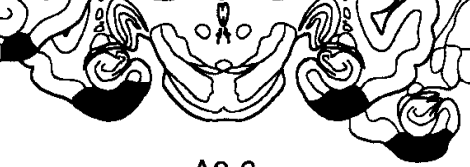

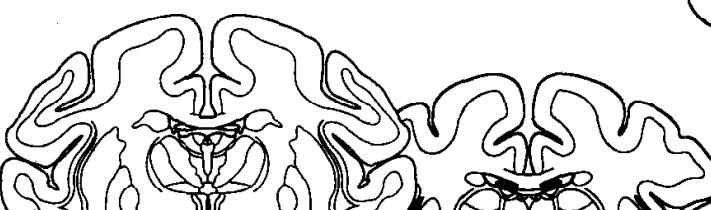

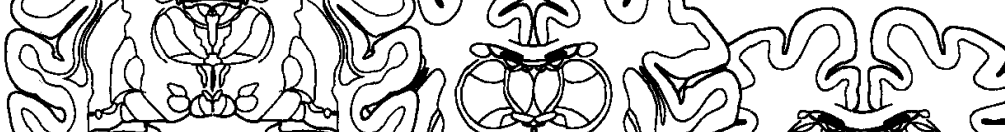

A20.0
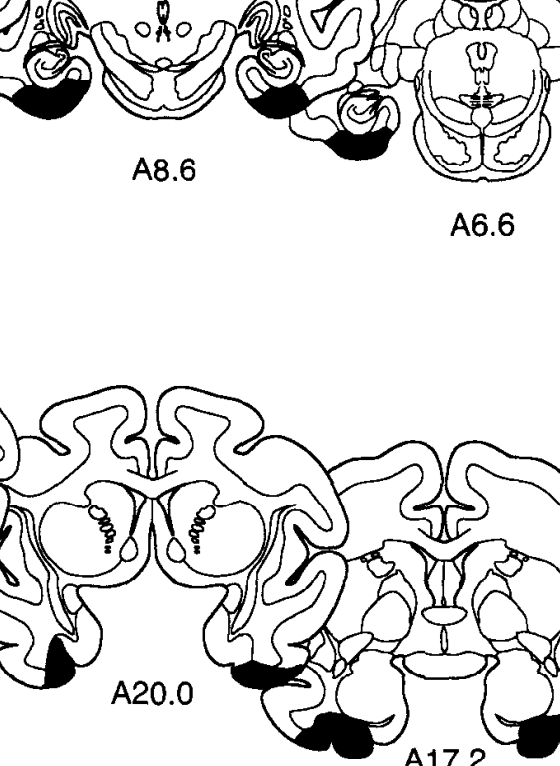

A6.6

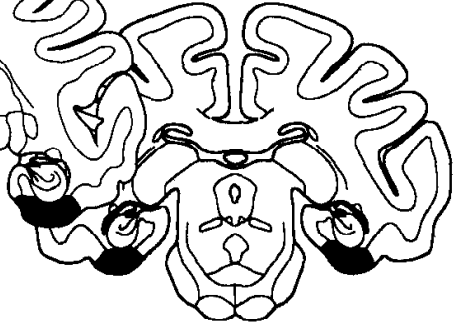

A4.6

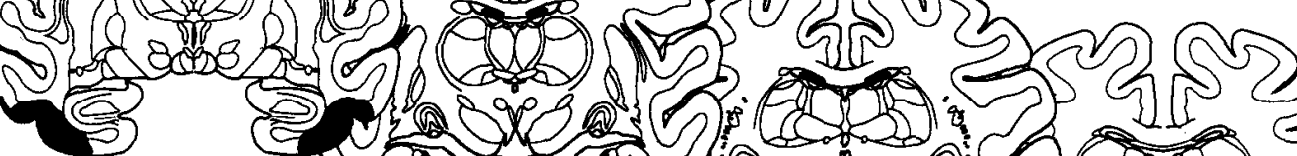

A13.4

A10.6

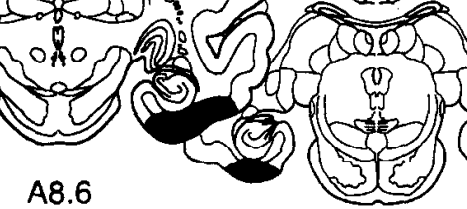

A6.6

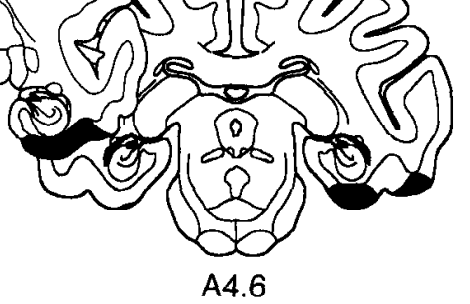

Figure 2. Continued. 

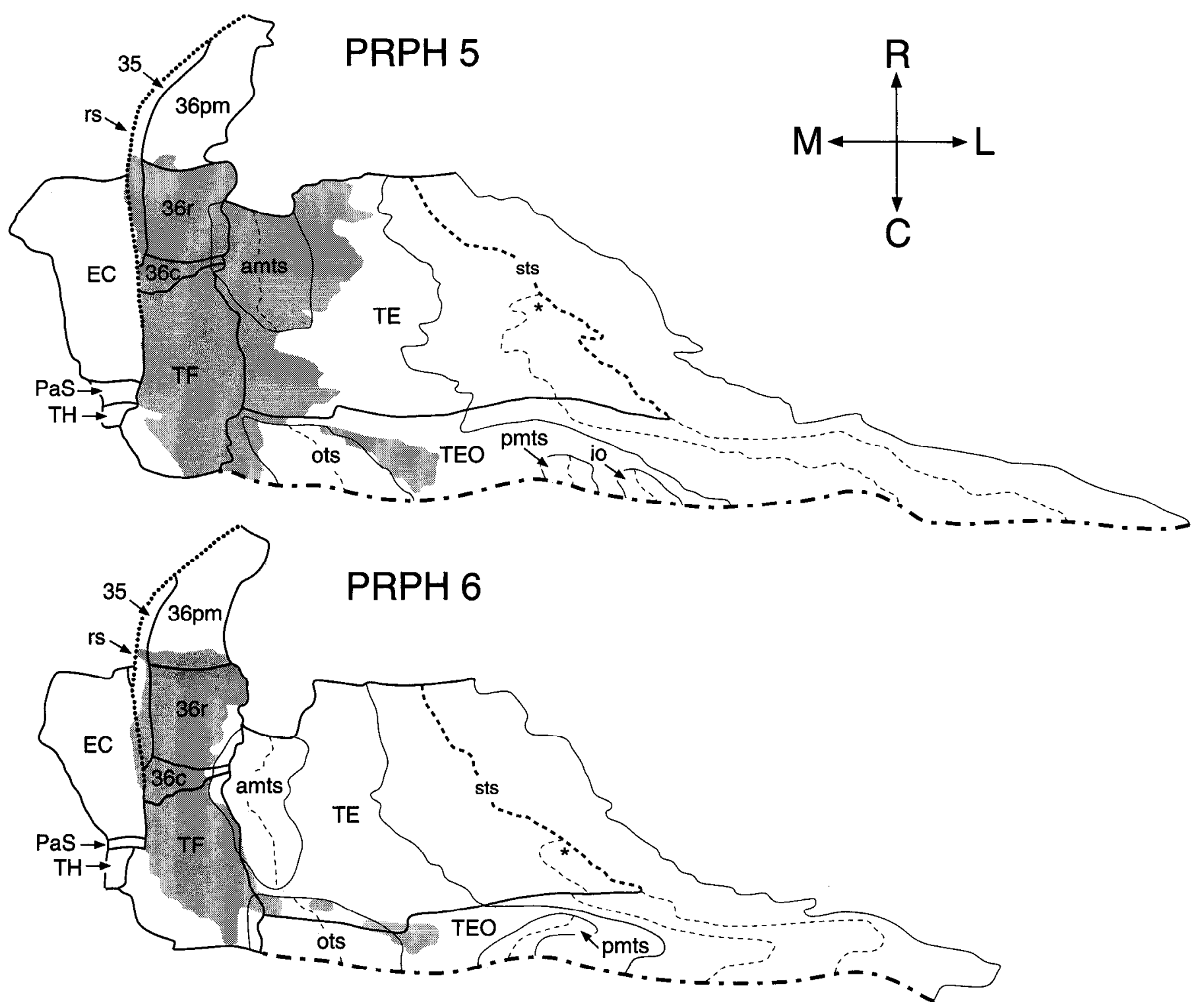

Figure 3. Unfolded two-dimensional maps of the right inferotemporal cortex for the four animals in the PRPH II group showing the entorhinal cortex $(E C)$, perirhinal cortex (areas 35,36pm, 36r, and $36 \mathrm{c}$ of Insausti et al., 1987), parahippocampal cortex (areas $T H$ and $T F$ as described in Insausti et al., 1987), and areas $T E$ and TEO (von Bonin and Bailey, 1947). The extent of the lesion is indicated as a shaded area. In this figure, $R$. $C, M$, and $L$ refer to rostral, caudal, medial, and lateral, respectively. A thick line represents the boundary of a cortical area, a thin line represents the medial or lateral bank of a sulcus, and a dashed line represents the fundus of a sulcus. The thick dashed line represents the fundus of the superior

$P R P H$ 8. The lesion in animal PRPH 8 resembled the lesion in animal PRPH 5. Through the rostrocaudal extent of the perirhinal cortex there was some involvement of area TE and also some involvement of the most lateral part of the entorhinal cortex on both sides. The white matter in this animal was transected bilaterally beginning at the mid-level of the amygdala (A17.2), Most of area TF was removed but much of area TH was spared. Through the level of the parahippocampal cortex, there was approximately the same amount of bilateral involvement of area TE and TEO as on the right side in animal PRPH 5. For a short rostrocaudal distance there was minor involvement of the ventral aspects of the lateral and paralaminar nuclei of the amygdala on the left side. In the hippocampus, the alveus and a small portion of area CA1 at the level of the genu on the left side were directly damaged. There also appeared to be a small amount of punctate cell loss in the subiculum on the right side. Finally, at the time of death it was found that this animal had sustained a preoperative skull wound over the left parietal cortex. The wound had apparently penetrated the skull and had caused direct damage to area $7 \mathrm{a}$ of the left parietal cortex.

\section{Comparison with lesions in the PRPH I group}

Overall, the PRPH lesions in the animals of the PRPH II group were more extensive than the lesions in the animals of the PRPH I group. The lesions in the PRPH II group consistently involved more of the mediolateral extent of both the perirhinal and parahippocampal cortices (compare Fig. 2 in the present study with Fig. 3 of Zola-Morgan et al., 1989c). The lesions in the PRPH II group also consistently extended more rostrally than the le- 


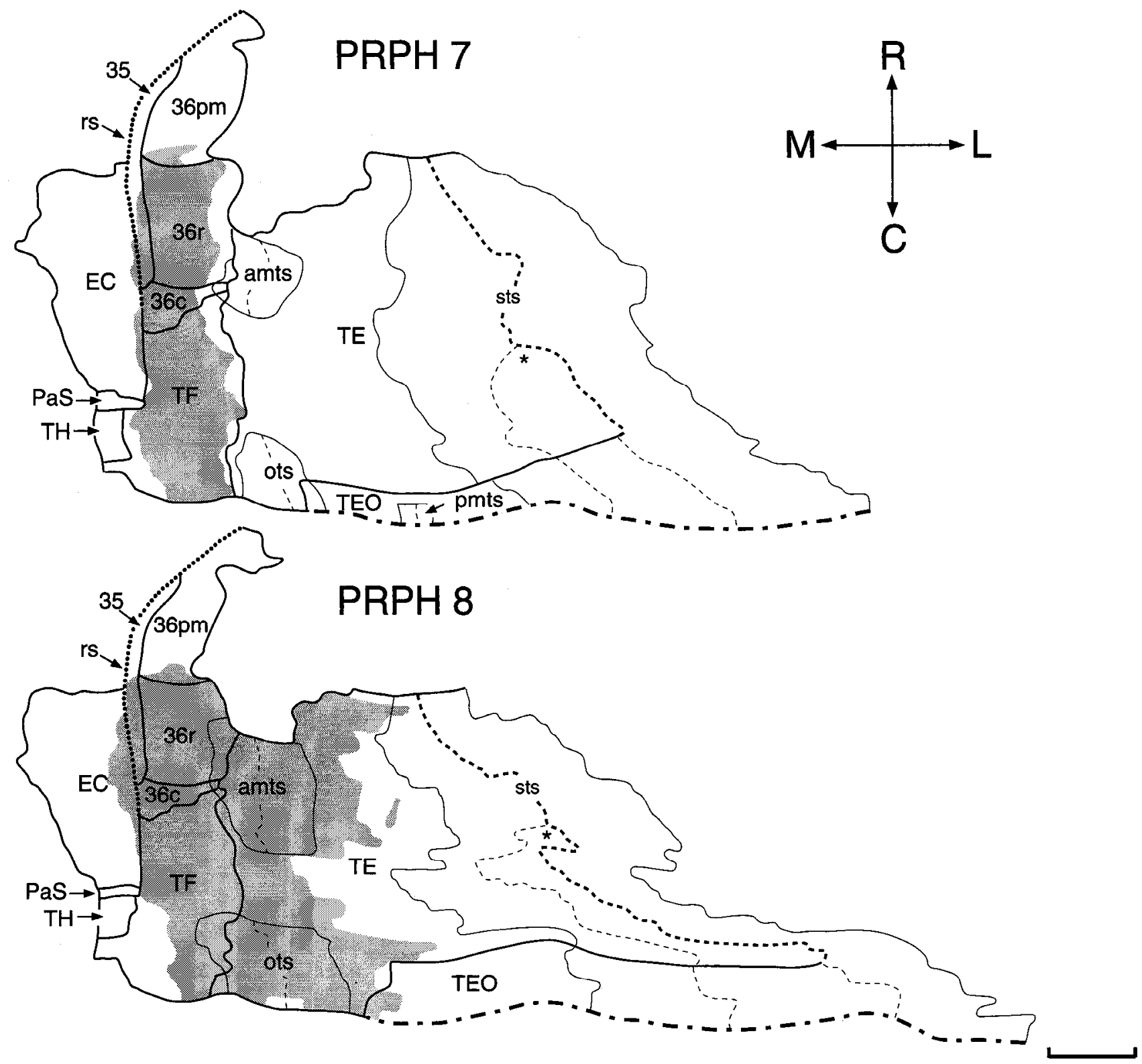

temporal sulcus, which is lateral border of area TE. The dotted line represents the fundus of the rhinal sulcus, and the dot-dashed line represents the caudal boundary of the map. Asterisk indicates the level at which the cortex of the superior temporal sulcus expands and folds and is represented in the maps as the splitting in two of the fundus of the superior temporal sulcus. amts, anterior middle temporal sulcus; io, inferior occipital sulcus; ots, occipitotemporal sulcus; $P a S$, parasubiculum; pmts, posterior middle temporal sulcus; $r s$, rhinal sulcus; sts, superior temporal sulcus. Scale bars, $5 \mathrm{~mm}$.

sions in the PRPH I group, involving more of the rostral perirhinal cortex. However, even the lesion in the PRPH II group involved only a small part of the temporal polar portion of the perirhinal cortex (area 36pm, Fig. 3).

The extent of damage to the white matter subjacent to the rhinal sulcus through the rostrocaudal extent of the entorhinal cortex was examined and quantified in both the PRPH I and PRPH II groups. Both the PRPH I and PRPH II groups sus- tained an average of $66 \%$ bilateral damage to this region of white matter (range for PRPH I group, 45-76\% damage; range for PRPH II group, 48-81\% damage). Moreover, the pattern of white matter damage was similar in the two PRPH groups. More than $90 \%$ of the spared white matter was situated in the rostral half of the entorhinal cortex while the caudal half of the entorhinal cortex retained virtually no spared white matter.

Finally, the amount of direct damage to the amygdala and

Figure 4. Photomicrographs of representative sections through the left and right temporal lobe of animal PRPH 7. The sections are arranged from rostral $(A)$ to caudal $(H)$, and the lesion is indicated by arrowheads at each level. The open arrow on the right side of $B$ indicates the site of a retrograde tracer injection (diamidino yellow) in the entorhinal cortex. $A$, amygdala; amts, anterior middle temporal sulcus; $E$, entorhinal cortex; $H$, hippocampus; ots, occipitotemporal sulcus; $r s$, rhinal sulcus; sts, superior temporal sulcus; $T E, T F$, $T H$, fields of von Bonin and Bailey (1947); $36 \mathrm{pm}$, polar medial field of area 36 of the perirhinal cortex after Insausti et al., (1987); $V$, ventricle. Scale bar, $3 \mathrm{~mm}$. 

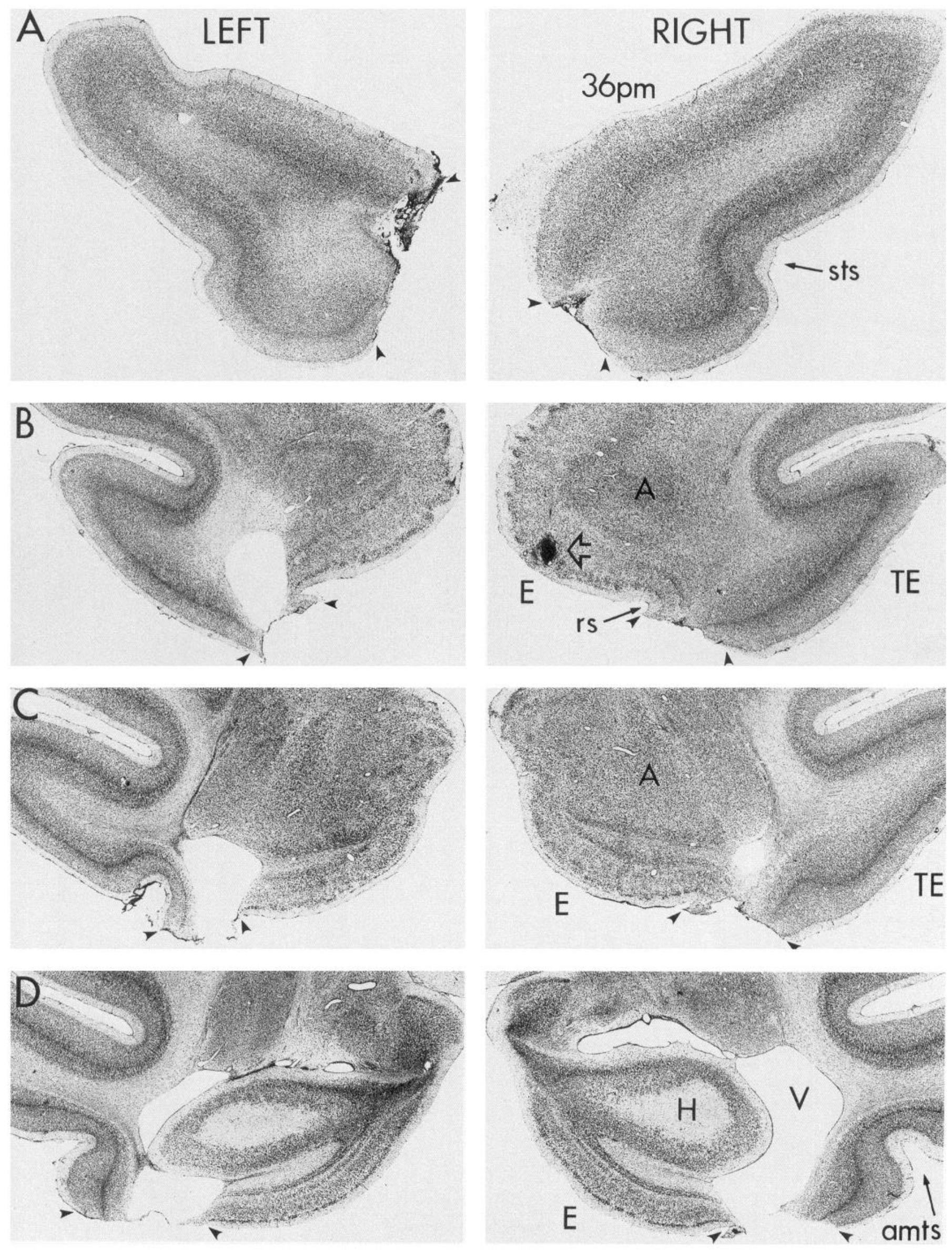

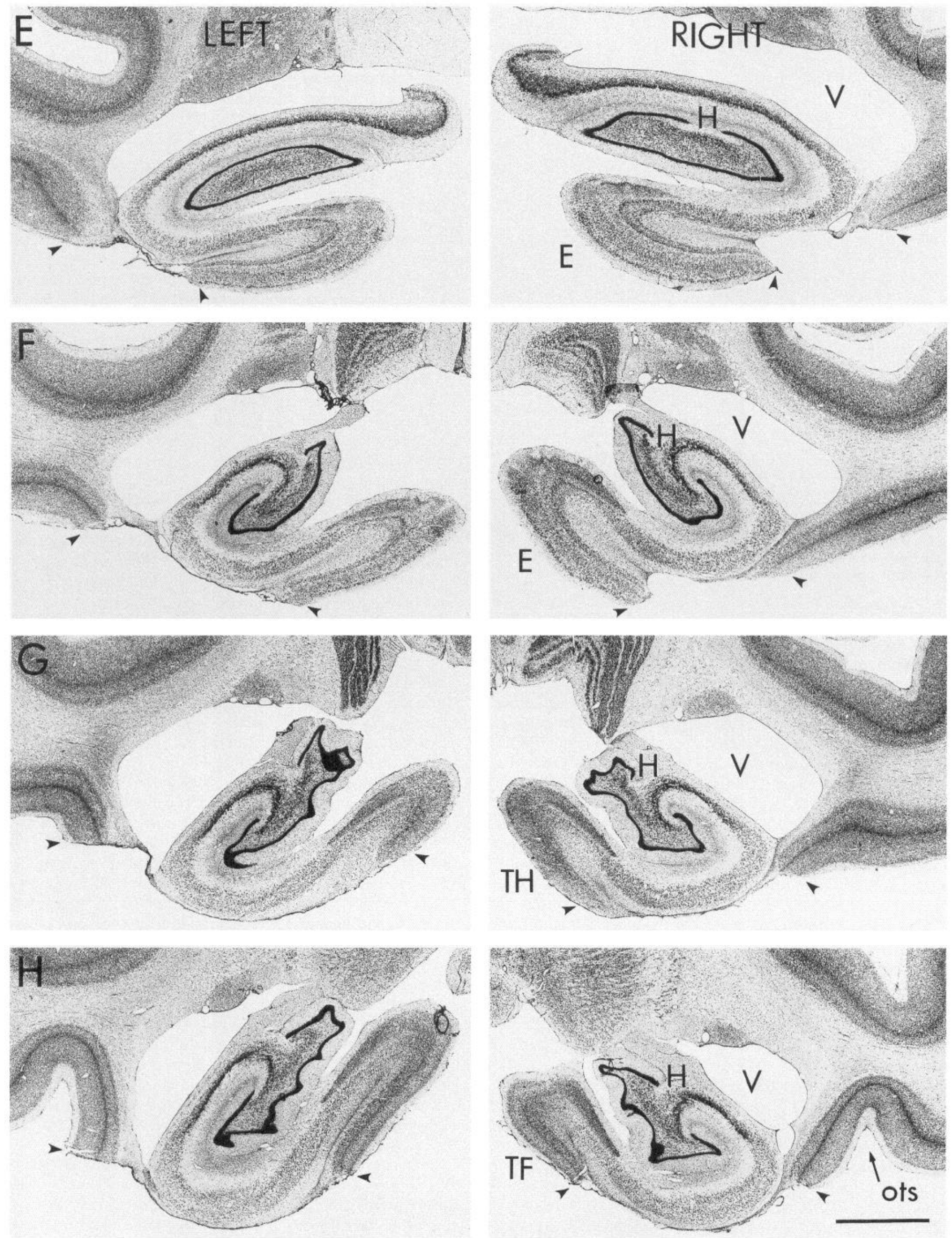


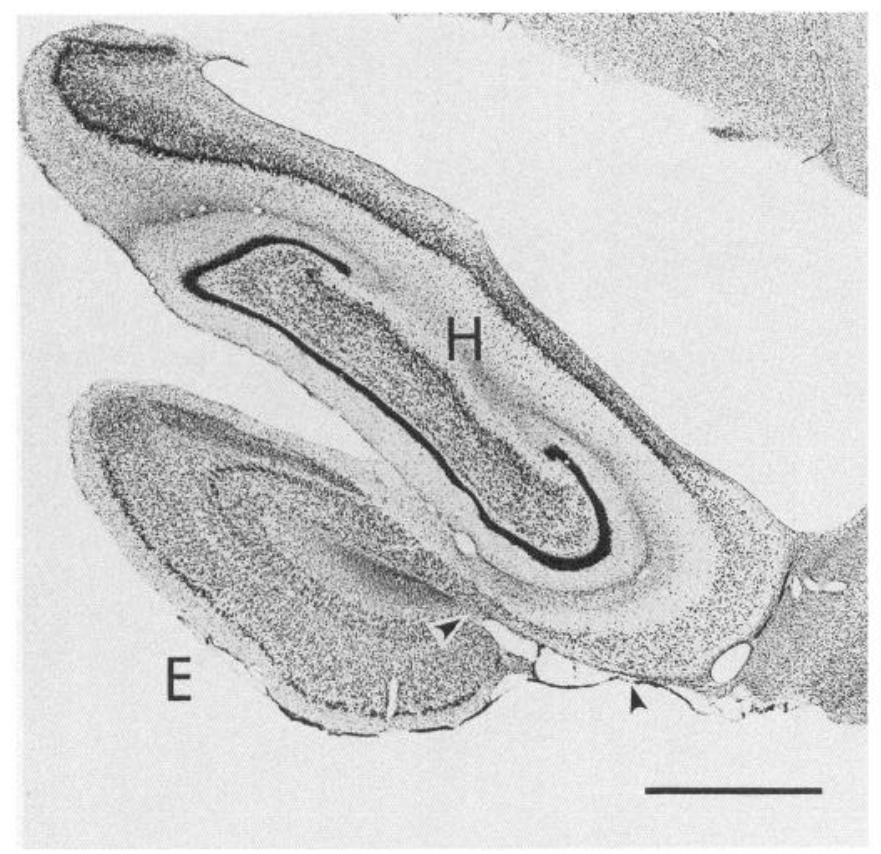

Figure 5. Photomicrograph of a representative section through the right hippocampus in animal PRPH 2 from the PRPH I group (ZolaMorgan et al., 1989c). The damaged region of the CAl-subicular border is indicated by arrowheads. In this section, approximately $1.8 \mathrm{~mm}$ of the CA1/subicular border was damaged, involving approximately $29 \%$ of the CA1 field and 44\% of the subiculum. $E$, entorhinal cortex; $H$, hippocampus. Scale bar, $2 \mathrm{~mm}$.

hippocampus in the PRPH I and PRPH II groups was examined. In both groups, the amygdala sustained little or no direct damage. In contrast, there was direct damage to portions of the hippocampus and subiculum in the PRPH I group while the PRPH II group sustained little or no such damage. The damage in the PRPH I animals was focused at the CAl/subicular border and included transection of the fibers of the alveus and some loss of pyramidal cells in this region (Fig. 5). To quantify the extent of this damage, sections through the full rostrocaudal extent of the hippocampus for each animal in the PRPH I and PRPH II groups were evaluated for the occurrence of damage. In the PRPH I group, animal PRPH 1 sustained some form of damage in $21 \%$ of the sections through the hippocampus on the left side and $0 \%$ of the sections through the hippocampus on the right. The corresponding figures for the other animals of the PRPH I group were PRPH $2=21 \%$ damage on the left, $53 \%$ damage on the right; PRPH $3=0 \%$ damage on the left, $18 \%$ damage on the right; PRPH $4=0 \%$ damage on the left, $24 \%$ damage on the right. It should be noted that the damage to the pyramidal cells of the CAl/subiculum border region in the animals of the PRPH I group involved a relatively small portion of the transverse extent of these fields in all cases (Fig. 5). To summarize, of the four animals that comprised the PRPH I group, one animal had bilateral damage to the $\mathrm{CAl} /$ subiculum border whereas the other three animals had mainly unilateral damage in this region. In contrast, three of the four animals in the PRPH II group sustained essentially no direct damage to the hippocampus, subiculum, or the alvcus. In the remaining animal in the PRPH II group (animal PRPH 8), the damage differed slightly from the damage observed in the PRPH I group. In the animals of the PRPH I group, there was typically coex- tensive damage to the alveus and pyramidal cells of the CAl/ subicular border region. In animal PRPH 8, there was direct damage to the pyramidal cells of the $\mathrm{CAl} /$ subicular border region bilaterally for approximately $6 \%$ of the length of the hippocampus. However, on the left side, the alveus was directly damaged for approximately $26 \%$ of the length of the hippocampus.

\section{Description of retrograde and anterograde tracer studies}

Animals PRPH 6, PRPH 7, and PRPH 8 received injections of the retrograde tracers diamidino yellow and fast blue into two different rostrocaudal levels of the entorhinal cortex on one side and an injection of a mixture of ${ }^{3} \mathrm{H}$-leucine and ${ }^{3} \mathrm{H}$-proline on the contralateral side. Because animal PRPH 6 died soon after surgery, neuroanatomical information is not available for this animal. For animals PRPH 7 and PRPH 8, one of the retrograde tracer injections was centered in the rostral subdivision of the entorhinal cortex (area $E_{R}$ as described in Amaral et al., 1987) and the second retrograde tracer injection was centered either in the olfactory subdivision of the entorhinal cortex (area $\mathrm{E}_{\mathrm{O}}$ as described in Amaral et al., 1987, for animal PRPH 8), or at the border between areas $E_{R}$ and $E_{O}$ (for animal PRPH 7). In both cases, the ${ }^{3} \mathrm{H}$-leucine and ${ }^{3} \mathrm{H}$-proline injection was situated in the area $E_{R}$ on the contralateral side. Because the pattern of labeling from the three tracer injections was similar in the two cases, only the results of the retrograde tracing studies for animal PRPH 7 will be described. Finally, in animal PRPH 5, the anterograde tracer DiI was placed at six different positions in the entorhinal cortex on the right side. The results from this case will also be briefly described.

The injection of the retrograde tracer fast blue in animal PRPH 7 was located at a mid-medial-lateral position in area $E_{R}$ of the entorhinal cortex on the left side and involved the deep layers of the entorhinal cortex and the white matter deep to the entorhinal cortex, as well as part of the paralaminar nucleus of the amygdala. At the level of the injection site, there was some intact white matter subjacent to the PRPH lesion, although the white matter became fully transected just caudal to the level of the injection site. In general, the pattern of labeling in cortical areas was similar to the labeling that would be expected from a similarly placed injection in a normal control animal (Insausti et al., 1987). In the frontal cortex, the heaviest labeling was observed in orbitofrontal areas 13 and $13 \mathrm{~A}$, with fewer labeled cells observed in areas 14 and 12 . There were also numerous labeled cells in the anterior cingulate cortex, and the insular cortex. In the temporal lobe, sparse labeling was observed in the dorsal bank of the superior temporal sulcus and superior temporal gyrus, but many labeled cells were observed in the spared temporal polar portion of the perirhinal cortex (area $36 \mathrm{pm}$ ). At more caudal levels of the temporal lobe, there were no retrogradely labeled cells observed in the spared lateral portion of the perirhinal or parahippocampal cortex, although a few labeled cells were observed in the spared rostral portion of area $\mathrm{TH}$. These findings suggest that, although the polar portion of the perirhinal cortex retained patent connections with the entorhinal cortex, the spared lateral portions of the perirhinal and parahippocampal cortices did not.

Subcortically, the density and pattern of retrogradely labeled cells were also similar to the labeling expected in a normal control animal. Within the hippocampal formation there were numerous labeled cells in the deep layers of the entorhinal cortex and at the CA1-subicular border region. Large numbers of la- 
beled cells were also observed in the claustrum, amygdala, medial septal area, and nucleus of the diagonal band. Fewer labeled cells were observed in the rostral intralaminar nuclei and mediodorsal nucleus of the thalamus. At least some of the labeling in the thalamic regions may have been due, in part, to contamination of the paralaminar nucleus of the amygdala.

The diamidino yellow injection in this animal was situated at the border between areas $E_{O}$ and $E_{R}$ of the entorhinal cortex on the left side. Overall the cortical and subcortical labeling following this injection resembled the labeling that would be expected from a similarly placed injection in area $E_{O}$ of an unoperated control animal. Similar to the pattern of labeling obscrved after the fast blue injection in $E_{R}$, there were also numerous diamidino yellow-labeled cells observed in the spared temporal polar portion of the perirhinal cortex, although no labeled cells were observed in the spared lateral aspect of area 36. At the level of the injection site, the white matter subjacent to the lesion was completely intact.

Finally, the anterograde tracer injection in area $E_{R}$ on the right side resulted in terminal labeling similar to the labeling that would be expected from a similarly placed injection in an unoperated control animal. In general, terminal labeling was observed in the same regions where labeled cells were found after the fast blue injection in area $E_{R}$ on the contralateral side.

In animal PRPH 5, crystals of the anterograde tracer Dil were placed at three rostrocaudal levels in the entorhinal cortex on the right side. Although the incubation time of 5 months was not long enough for the dye to be transported to the axon terminals, the dye was transported between 4 and $7 \mathrm{~mm}$ away from the DiI placement sites. Through the rostral half of the entorhinal cortex, labeled axons were observed traveling in the spared white matter ventral and lateral to the amygdala. Although the location of the terminals of these axons could not be identified, these data confirm the observations in animals PRPH 7 and PRPH 8 that at rostral levels of the entorhinal cortex, where the white matter was spared, there were also spared connections between the entorhinal cortex and the rest of the neocortex. Through the caudal half of the entorhinal cortex in animal PRPH 5 , there appeared to be a small amount of spared white matter (see Histological results). In this caudal area, no labeled fibers were observed lateral to the lesion, suggesting that this small amount of spared white matter was not carrying the axons of the entorhinal cortex.

In summary, the findings from the tracer experiments indicate that, although the source of the major cortical input to the entorhinal cortex was eliminated by the PRPH lesion, the rostral part of the entorhinal cortex $\left(E_{0}\right.$ and $\left.E_{R}\right)$, where the white matter was spared, still retained patent connections with other neocortical areas such as the spared temporal polar portion of the perirhinal cortex, the dorsal bank of the superior temporal sulcus, the insular cortex, and the cingulate cortex. At caudal levels of the entorhinal cortex, however, not only were most of the connections with the perirhinal and parahippocampal cortices eliminated by the PRPH lesion, but the transection of the white matter subjacent to the rhinal sulcus also eliminated most of the connectivity with other cortical areas.

\section{Behavioral results}

Visual delayed nonmalching to sample wilh double-sample presentation. Figure $6 A$ (left) shows the mean number of trials required to reach criterion level performance on the basic task with an $8 \mathrm{sec}$ delay. Individual scores for the PRPH II group
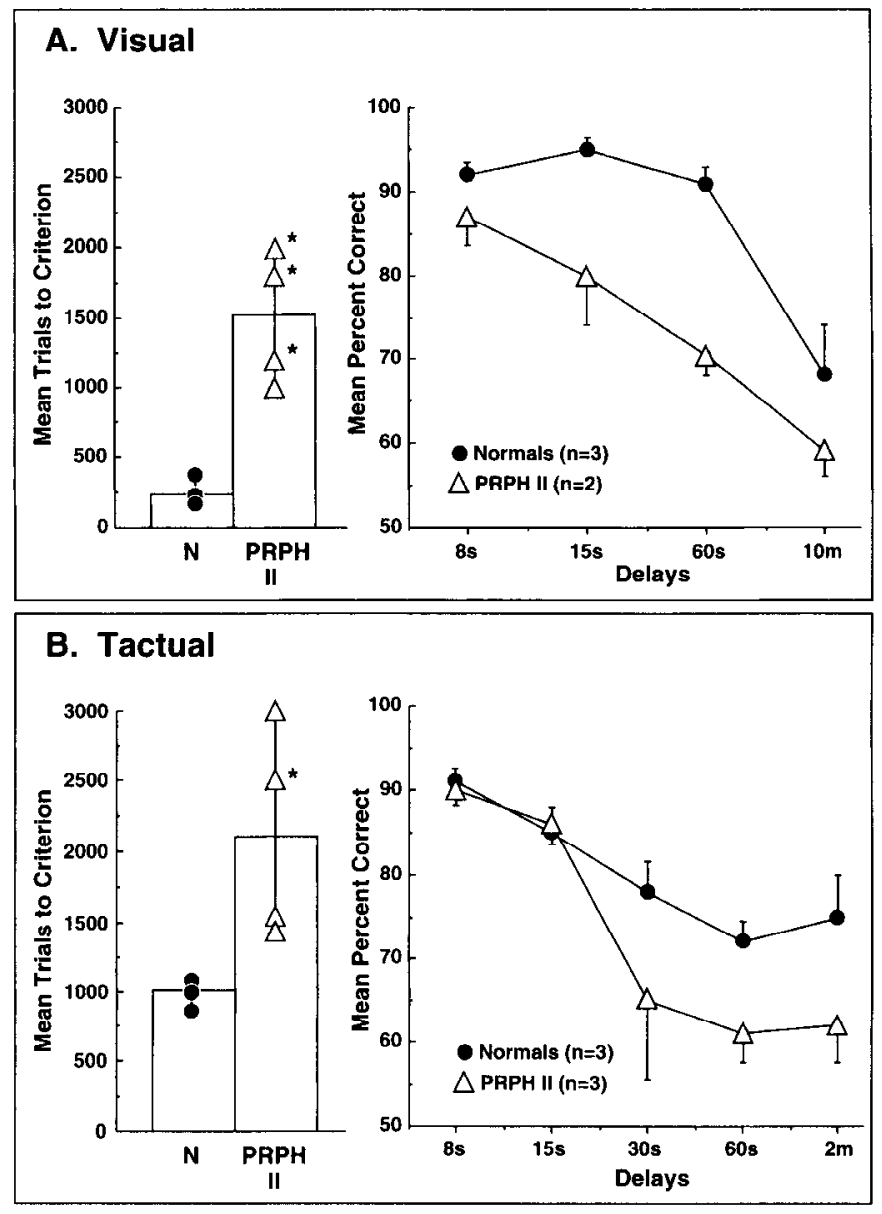

C. Visual Retest

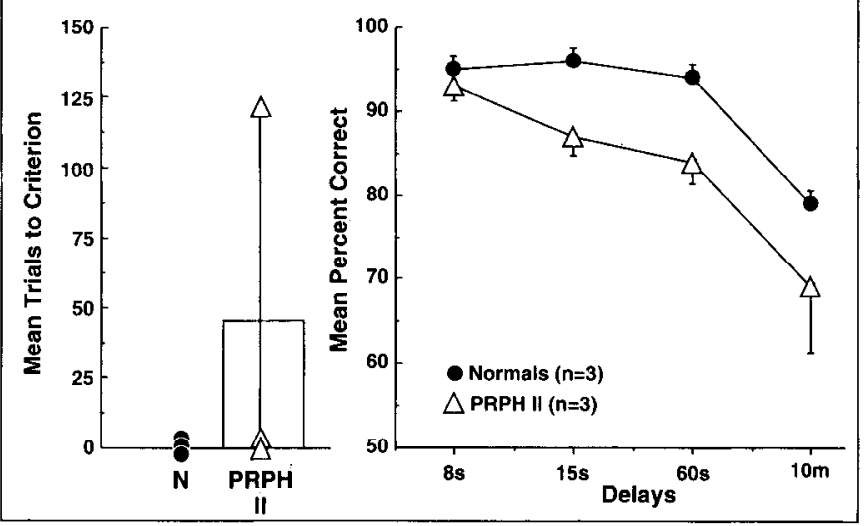

Figure 6. Performance on the visual $(A)$, tactual $(B)$, and visual retest $(C)$ of the DNMS task by normal monkeys $(N)$ and animals with lesions of the perirhinal and parahippocampal cortices (PRPH II). The graph on the left of each panel shows the initial learning of the task with a delay of $8 \mathrm{sec}$. Symbols show trials to criterion for individual animals (see Table 1). Asterisks indicate animals that did not reach criterion level performance on the basic task. The graph on the right of each panel shows the performance across delays for the same groups. SE bars are given for each group at each delay (see Behavioral results for details).

and the $\mathrm{N}$ group are given in Table 1 . The scores of the animals in the PRPH I group are also shown for comparison. Of the four animals in the PRPH II group, only animal PRPH 6 was able to reach criterion level performance $(90 \%$ correct in 100 consecutive trials) on the basic task. Animal PRPH 8 was per- 
Table 1. Delayed nonmatching to sample

\begin{tabular}{|c|c|c|c|c|c|c|c|c|c|c|c|c|c|c|c|c|}
\hline \multirow[b]{3}{*}{ Group } & \multicolumn{5}{|l|}{ Visual } & \multicolumn{6}{|l|}{ Tactual } & \multicolumn{5}{|c|}{ Visual retest } \\
\hline & \multirow[b]{2}{*}{$\begin{array}{l}\text { Trials to } \\
\text { criternou }\end{array}$} & \multicolumn{4}{|c|}{ Delays } & \multirow[b]{2}{*}{$\begin{array}{l}\text { Trials to } \\
\text { criterion }\end{array}$} & \multicolumn{5}{|c|}{ Delays } & \multirow[b]{2}{*}{$\begin{array}{l}\text { Trials to } \\
\text { criterion }\end{array}$} & \multicolumn{4}{|c|}{ Delays } \\
\hline & & $\begin{array}{l}8 \\
\text { and }\end{array}$ & 15 & $\begin{array}{l}60 \\
: \therefore=\end{array}$ & $\begin{array}{l}10 \\
\cdots\end{array}$ & & $\begin{array}{l}8 \\
\text { sec }\end{array}$ & $\begin{array}{l}15 \\
\mathrm{sec}\end{array}$ & $\begin{array}{l}30 \\
\mathrm{sec}\end{array}$ & $\begin{array}{l}60 \\
\mathrm{sec} \\
\end{array}$ & $\begin{array}{l}2 \\
\min \\
\end{array}$ & & $\begin{array}{l}8 \\
\text { sec }\end{array}$ & $\begin{array}{l}15 \\
\mathrm{sec}\end{array}$ & $\begin{array}{l}60 \\
\text { sec } \\
\end{array}$ & $\begin{array}{l}10 \\
\min \end{array}$ \\
\hline \multicolumn{17}{|l|}{ Normal } \\
\hline 1 & 380 & 91 & 96 & 88 & 62 & 1099 & 90 & 80 & 71 & 74 & 67 & 0 & 95 & 95 & 91 & 80 \\
\hline 2 & 140 & 92 & 96 & 91 & 62 & 1026 & 92 & 90 & 79 & 67 & 74 & 0 & 93 & 94 & 94 & 78 \\
\hline 3 & 200 & 92 & 94 & 95 & 80 & 860 & 90 & 86 & 83 & 75 & 84 & 0 & 97 & 99 & 96 & 80 \\
\hline Mean & 240 & 92 & 95 & 91 & 68 & 995 & 91 & 85 & 78 & 72 & 75 & 0 & 95 & 96 & 94 & 79 \\
\hline \multicolumn{17}{|l|}{ PRPH II } \\
\hline 5 & $1830^{a}$ & $68^{b}$ & $83^{b}$ & $62^{b}$ & $46^{b}$ & 1453 & 90 & 83 & 71 & 67 & 69 & 0 & 91 & 83 & 86 & 84 \\
\hline 6 & 1020 & 90 & 86 & 73 & 56 & 2970 & 90 & 91 & 78 & 56 & 54 & 120 & 91 & 86 & 79 & 58 \\
\hline 7 & $2000^{a}$ & 83 & 74 & 68 & 62 & 1550 & 90 & 84 & 47 & 59 & 63 & 0 & 96 & 91 & 88 & 66 \\
\hline 8 & $1200^{\alpha}$ & - & - & - & - & $2500^{\alpha}$ & - & - & - & - & - & $1100^{a . b}$ & - & - & - & - \\
\hline Mean & 1513 & 87 & 80 & 71 & 59 & 2118 & 90 & 86 & 65 & 61 & 62 & 40 & 93 & 87 & 84 & 69 \\
\hline \multicolumn{17}{|l|}{ PRPH I } \\
\hline $1^{c}$ & 580 & 91 & 89 & 84 & 76 & - & - & - & - & - & - & - & - & - & - & - \\
\hline $2^{d}$ & 1100 & 91 & 72 & 69 & 64 & - & - & - & - & - & - & - & - & - & - & - \\
\hline $3^{d}$ & 1680 & 92 & 81 & 73 & 40 & - & - & - & - & - & - & - & - & - & - & - \\
\hline $4^{d}$ & $2000^{a}$ & - & - & - & - & - & - & - & - & - & - & - & - & - & - & - \\
\hline Mean & 1340 & 91 & 81 & 75 & 60 & - & - & - & - & - & - & - & - & - & - & - \\
\hline
\end{tabular}

PRPH I and PRPH II, monkeys with bilateral lesions of the perirhinal and parahippocampal cortices.

a This animal did not reach learning criterion, and training was discontinued.

"This scorc was not included in the mean for the PRPH II group either here or in Figure 6 (see Behavioral results).

- This animal received single-sample presentation during training on the basic task and on the delay portion of the task.

${ }^{\prime}$ This animal received single-sample presentation for the first 1000 trials of training on the basic task. At this time, the animal had not reached criterion level performance and the double-sample presentation procedure was given. The double-sample presentation procedure was continued during testing on the delays.

forming at $50 \%$ correct during the last 100 trials when testing was discontinued after 1200 trials. Animal PRPH 5 was performing at $68 \%$ correct when testing was discontinued after 1830 trials. This animal experienced motivational problems throughout testing on the DNMS task, sometimes completing only 10 trials per day. Animal PRPH 7 was performing at $83 \%$ correct during the last 100 trials when testing was discontinued after 2000 trials. Compared to the three monkeys in the $\mathrm{N}$ group, the four monkeys in the PRPH II group were significantly impaired in their ability to learn the basic task (mean trials to criterion: N, 240; PRPH II, 1513; $P<0.01$ ).

Figure $6 A$ (right) shows the performance of animal PRPH 6, who was able to reach criterion level performance on the basic task, animal PRPH 7 who was able to achieve a score of $83 \%$ on the last 100 trials of the basic task, and the $\mathrm{N}$ group as the delay intervals were increased from $8 \mathrm{sec}$ to $10 \mathrm{~min}$. Table 1 shows scores for each animal. Animal PRPH 8 was not tested on the delay intervals. Because animal PRPH 5 did not master the basic task $(68 \%$ correct at the end of training on the basic task), this monkey's scores on the delay portion of the task were not included in the statistical analyses (see below). A two-way ANOVA involving two groups (N group and PRPH II group) and three delays $(15 \mathrm{sec}, 60 \mathrm{sec}$, and $10 \mathrm{~min}$ ) revealed a significant effect of group $[F(1,3)=19.68, P<0.05]$ and delay $[F(2,6)$ $=22.57, P<0.01 \mathrm{~J}$, and no significant group $\times$ delay interaction $[F(2,6)=1.14, P>0.1]$. Separate comparisons based on each group's scores at cach of the delays revealed that the PRPH II group performed significantly worse than the $N$ group at the 15 sec delay (N, 95\%; PRPH II, 80\%; $P<0.05$ ) and at the $60 \mathrm{sec}$ delay (N, 91\%; PRPH II, 71\%; $P<0.01$ ). At the 10 min delay, the performance of the PRPH II group was numerically worse than that of the $\mathrm{N}$ group, but this difference did not reach statistical significance (N, 68\%; PRPH II, 59\%; $P>0.1$ ).

Although animal PRPH 5 did not reach criterion on the basic task, this animal was nevertheless tested on the delay portion of the task. At the $15 \mathrm{sec}$ delay, monkey PRPH 5 obtained a score of $83 \%$ correct, which is within the range of scores for animals PRPH 6 and PRPH 7 at this delay. When the delays were further increased to $60 \mathrm{sec}$ and $10 \mathrm{~min}$, this animal's performance dropped to $62 \%$ and $46 \%$ correct, respectively. This marked decline in performance at the longest delays paralleled the pattern of performance of animals PRPH 6 and PRPH 7 on these delays. The results of the statistical analyses did not change if the scores of animal PRPH 5 were included.

In summary, compared to the $\mathrm{N}$ group, the PRPH II group exhibited a severe deficit on the visual version of the DNMS task, both in learning the basic task and in performing across increasing delay intervals.

Visual pattern discrimination. Because the two pattern discrimination problems proved to be equally difficult, the numbers of trials required to learn each problem were averaged together for each monkey (Fig. 7; animal N3 performed continuously at chance level on both problems, and testing on each problem was discontinued after 1000 trials. This animal was given an average score of 1000 . Animal PRPH 5 learned the first problem in 510 trials, but performed continually at chance levels on the second problem until testing was discontinued after 1000 trials. This animal was given an average score of 755). A comparison of the mean number of trials to reach criterion on the two pattern discrimination problems for the PRPH II group 


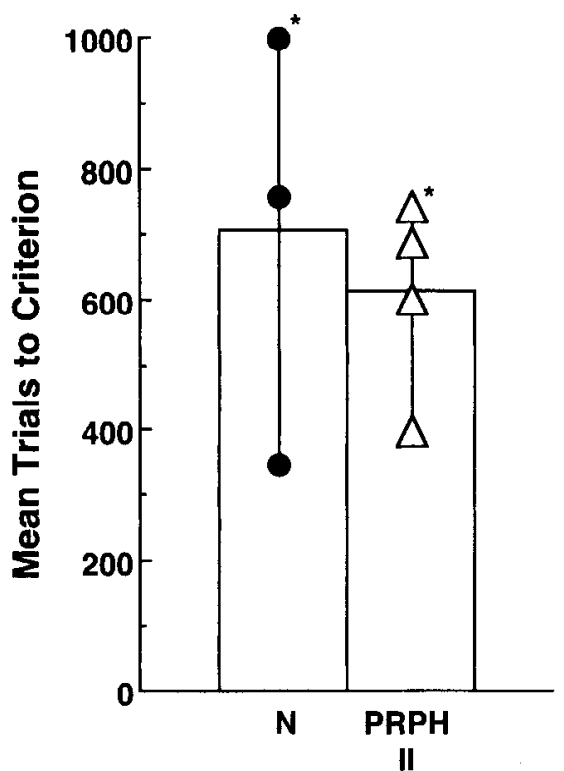

Figure 7. Average score on two pattern discrimination tasks by normal monkeys $(N)$ and monkeys with lesions of the perirhinal and parahippocampal cortices (PRPH II). Symbols show scores for individual monkeys. Asterisks indicate animals that did not reach criterion level performance on one or both pattern discrimination problems within 1000 trials (see Behavioral results for details).

and the $\mathrm{N}$ group revealed no significant difference (mean number of trials to criterion for patterns I and II: N, 707; PRPH II, 609; $P>0.1)$.

Visual delayed retention of object discriminations. The data for the three object discriminations were averaged together, and the mean percentage correct score was calculated for each day of testing (Fig. 8). Individual scores for the PRPH II group and the $\mathrm{N}$ group are given in Table 2. The scores of the animals in the PRPH I group are also shown for comparison. Two of the four animals in the PRPH II group performed outside the range of the $\mathrm{N}$ group on day 1 of testing (performance on day 1: PRPH $7=55 \%$ correct, PRPH $8=62 \%$ correct; range of scores for the $\mathrm{N}$ group: $65-73 \%$ correct) and one animal (PRPH 8) performed outside the range of normal animals on day 2 of testing (performance on day 2: PRPH $8=83 \%$ correct, range of scores of the $\mathrm{N}$ group $-87-93 \%$ ). However, a two-way ANOVA involving the PRPH II group, the $\mathrm{N}$ group, and the three days of testing revealed no group effect $[F(1,5)=0.53, P>0.1]$. Separate comparisons of performance between groups on day 1 , day 2 , day 4 , and the mean of $3 \mathrm{~d}$ also revealed no significant differences (day 1, day 2, and mean of $3 \mathrm{~d}: P>0.1$; day $4: P=0.08$ ).

Tactual object discrimination. Because the four tactual discrimination problems proved to be equally difficult, the numbers of trials required to learn the four discriminations were averaged together for each monkey (Fig. 9). The number of trials required by the two groups to reach criterion was similar (mean number of trials to criterion for the four tactual discrimination problems: $\mathrm{N}, 42$, range $30-57$; PRPH II, 40, range 25-60; $P>$ $0.1)$.

Tactual delayed nonmatching to sample with single sample presentation. Figure $6 B$ (left) shows the mean number of trials required to reach criterion on the basic task with an $8 \mathrm{sec}$ dclay. Individual scores are given in Table 1. Of the four animals in the PRPH II group, only animal PRPH 8 did not learn the basic task. This animal was performing at $53 \%$ when testing was

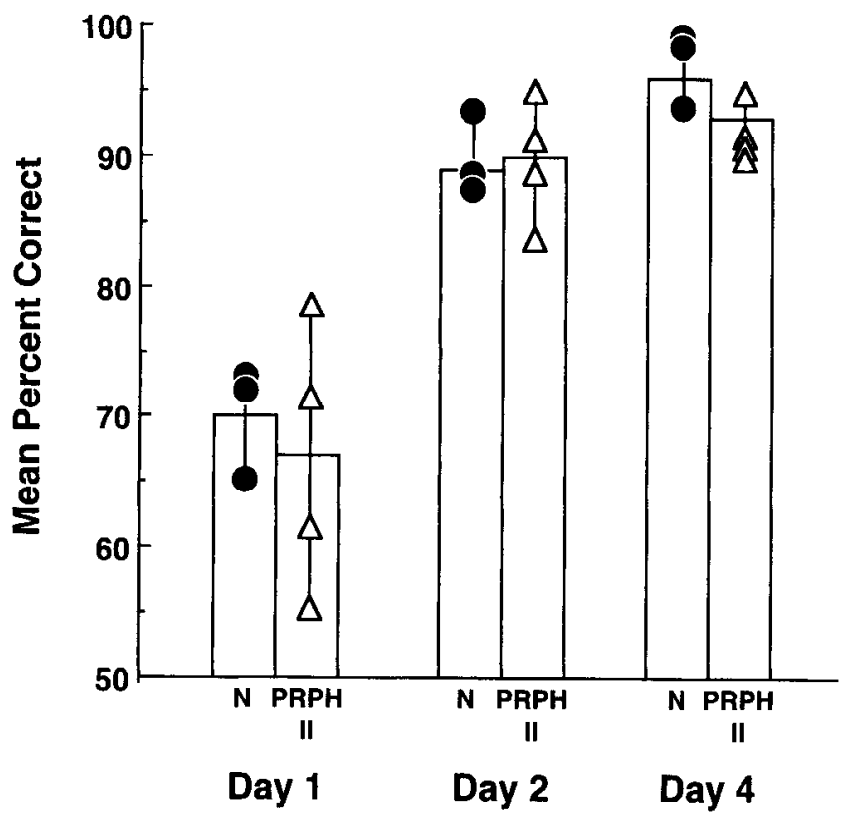

Figure 8. Average daily performance on three object discrimination tasks by normal monkeys $(N)$ and monkeys with lesions of the perirhinal and parahippocampal cortices (PRPH II). Symbols show scores for individual monkeys (see Table 2).

discontinued after 2500 trials. The remaining three animals in the PRPH II group, as well as all three animals in the $\mathrm{N}$ group, learned the basic task to criterion. Compared to the animals in the $\mathrm{N}$ group, the animals in the PRPH II group were significantly impaired in their ability to learn the basic task (mean trials to criterion: N, 995; PRPH II, 2118; $P=0.05$ ).

\begin{tabular}{|c|c|c|c|c|c|}
\hline \multirow[b]{2}{*}{ Group } & \multicolumn{4}{|c|}{$\begin{array}{l}\text { Delayed retention of } \\
\text { object discrimination }\end{array}$} & \multirow{2}{*}{$\begin{array}{l}\begin{array}{l}\text { Concurrent } \\
\text { discrimination }\end{array} \\
\begin{array}{l}\text { Trials to } \\
\text { criterion }\end{array}\end{array}$} \\
\hline & Day 1 & Day 2 & Day 4 & $\begin{array}{l}\text { Mean of } \\
3 \text { days }\end{array}$ & \\
\hline \multicolumn{6}{|l|}{ Normal } \\
\hline 1 & 65 & 88 & 93 & 82 & $1760^{a}$ \\
\hline 2 & 73 & 87 & 98 & 86 & 480 \\
\hline 3 & 72 & 93 & 98 & 88 & 340 \\
\hline Mean & 70 & 89 & 96 & 85 & 660 \\
\hline \multicolumn{6}{|l|}{ PRPH II } \\
\hline 5 & 78 & 95 & 92 & 88 & 720 \\
\hline 6 & 72 & 92 & 92 & 85 & 400 \\
\hline 7 & 55 & 88 & 95 & 79 & 440 \\
\hline 8 & 62 & 83 & 92 & 79 & $1840^{a}$ \\
\hline Mean & 67 & 90 & 93 & 83 & 520 \\
\hline \multicolumn{6}{|l|}{ PRPH I } \\
\hline 1 & 70 & 83 & 88 & 80 & - \\
\hline 2 & 76 & 70 & 72 & 73 & $1200^{a}$ \\
\hline 3 & 69 & 73 & 70 & 71 & - \\
\hline 4 & 50 & 68 & 85 & 68 & $1200^{a}$ \\
\hline Mean & 66 & 74 & 79 & 73 & 1200 \\
\hline
\end{tabular}

PRPH I and PRPH II, monkeys with bilateral lesions of the perirhinal and parahippocampal cortices.

- This animal did not reach learning criterion, and training was discontinued. This score was not included in the mean for the normal group or the PRPH II group. 


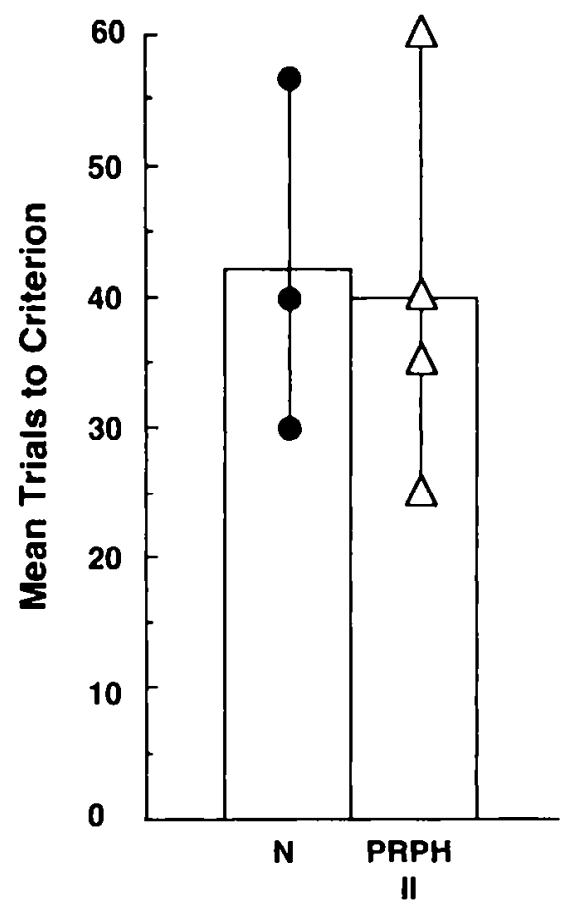

Figure 9. Average performance on four tactual object discrimination problems by normal monkeys $(N)$ and monkeys with lesions of the perirhinal and parahippocampal cortices (PRPHII). Symbols show scores for individual monkeys.

Table 1 shows the scores of individual animals as the delay interval was increased from $8 \mathrm{sec}$ to $2 \mathrm{~min}$. At the $10 \mathrm{~min}$ delay, neither the PRPH II group nor the $\mathrm{N}$ group performed significantly above chance levels (mean performance on the $10 \mathrm{~min}$ delay: N, 63\% correct; PRPH II, 59\% correct; $P>0.1$ ). Becausc chance level performance precludes the possibility of differentiating the performance of the two groups, this delay was not included in the following statistical analyses.

Figure $6 B$ (right) shows the performance of the PRPH II group and the $\mathrm{N}$ group on the tactual DNMS task as the delay interval was increased from $8 \mathrm{sec}$ to $2 \mathrm{~min}$. Animal PRPH 8 was not tested on the delays. An ANOVA involving the two groups (N group and PRPH II group) and four delays (15 sec, $30 \mathrm{sec}, 60$ sec, and $2 \mathrm{~min}$ ) revealed a group effect that fell just short of significance $[F(1,4)=5.68, P=0.076]$. Separate comparisons of the two groups at individual delays revealed that the PRPH II group performed numerically worse than the $\mathrm{N}$ group at the $30 \mathrm{sec}$ delay (N, 78\%; PRPH II, 65\%), 60 sec delay (N, 72\%; PRPH II, 61\%), and 2 min delay (N, 75\%; PRPH II, 62\%). The comparison reached statistical significance at the $60 \mathrm{sec}$ delay $(P=0.05)$.

Retest of visual delayed nonmatching to sample with doublesample presentation. Figure $6 C$ (left) shows the mean number of trials to reach criterion on the basic task when the visual DNMS task was readministered. Individual scores are given in Table 1. Three of the four PRPH II animals were able to relearn the visual DNMS task to criterion. Animal PRPH 8, who did not learn the task the first time it was given $(50 \%$ correct after 1200 trials), also did not learn the task the second time it was given $(62 \%$ correct on the last 100 trials when testing was discontinued after 1100 trials). This animal's score is not included in the following statistical analyses. There was no difference in the number of trials to relearn the visual DNMS task for the
PRPH II group (animals PRPH 5, 6, and 7) and the $\mathrm{N}$ group (mean trials to criterion: N, 0; PRPH II, 40; $P>0.1$ ).

Figure $6 C$ (right) shows the performance of the PRPH II group and the $\mathrm{N}$ group as the delay intervals were increased from 8 sec to $10 \mathrm{~min}$. Animal PRPH 8 was not tested on the delay intervals. Individual scores are given in Table 1. A two-way ANOVA involving the two groups ( $\mathrm{N}$ group and PRPH II group) and three delays $(15 \mathrm{sec}, 60 \mathrm{sec}$, and $10 \mathrm{~min}$ ) revealed a significant effect of group $[F(1,4)=9.19, P<0.05]$ and delay $[F(2,8)$ $=14.43, P<0.01]$, and no significant group $\times$ delay interaction $[F(2,8)=0.01, P>0.1]$. Separate comparisons based on each group's scores across the delays revealed that the PRPH II group performed significantly worse than the $\mathrm{N}$ group at the $15 \mathrm{sec}$ delay (N, 96\%; PRPH II, $87 \% ; P<0.05)$ and at the $60 \mathrm{sec}$ delay (N, 94\%; PRPH II, 84\%; $P<0.05$ ). At the $10 \mathrm{~min}$ delay, the PRPH II group also performed numerically worse than the $N$ group, but this difference did not reach statistical significance (N, 79\%; PRPH II, 69\%; $P>0.1$ ).

Next, the delay performance on the visual DNMS task the first time it was given was compared to the delay performance the second time it was given for both the $\mathrm{N}$ group and animals PRPH 6 and PRPH 7 (the two animals who learned the DNMS task both times it was given). The $\mathrm{N}$ group performed similarly on both occasions (mean of three longest delays: first test, $85 \%$, second test, $90 \% ; P>0.1)$. Similarly, although animals PRPH 6 and PRPH 7 exhibited some numerical improvement in their performance at the $15 \mathrm{sec}$ and 60 scc dclays, there was no overall change in performance on delays (mean of three delays: first test, $70 \%$; second test, $78 \% ; P>0.1$ ). Notably, the mean performance score for animals PRPH 6 and PRPH 7 on the retest of the 10 min delay was within $3 \%$ of their original performance score (first test, $59 \%$; second test, $62 \% ; P>0.1$ ).

In summary, the PRPH II group and the $N$ group did not differ in their ability to relearn the visual DNMS task to criterion levels. However, compared to the $\mathrm{N}$ group, the PRPH II group continued to exhibit a significant deficit on delays. Finally, there was no significant difference in delay performance for the PRPH II group on the two occasions that the DNMS task was given separated by 2 years. This finding was also obtained for the $\mathrm{N}$ group.

Concurrent discrimination. Figure 10 shows the mean number of trials to reach criterion on the concurrent discrimination task for the $\mathrm{N}$ group and the PRPH II group. Individual scores are shown in Table 2. The scores of the animals in the PRPH I group are also given for comparison. Animal PRPH 8 was performing at $68 \%$ correct during the last two sessions when testing was stopped after 1840 trials. Animal NI was performing at $79 \%$ correct during the last two sessions when testing was stopped after 1760 trials. A comparison of the number of trials needed to reach criterion by the $N$ group (animals $N 2$ and N3) and the PRPH II group (animals PRPH 5, PRPH 6, and PRPH 7) revealed no significant difference $(P>0.1)$. The statistical finding did not change if the scores of animals $N 1$ and PRPH 8 were included.

\section{Discussion}

Monkeys with bilateral lesions limited to the perirhinal and parahippocampal cortices (the PRPH lesion) were severely impaired on both visual and tactual versions of the DNMS task. Moreover, the memory impairment was long-lasting. Monkeys with PRPH lesions continued to exhibit impaired performance when retested on the visual version of the DNMS task approximately 2 years after surgery. The animals in the PRPH II group 
were unimpaired on a visual pattern discrimination task and a simple tactual discrimination task. These findings suggest that the impairment on the DNMS tasks was not due to perceptual deficits in either the visual or the tactual modality. When compared to the three normal monkeys in the present study, the monkeys in the PRPH II group were unimpaired on an additional task known to be sensitive to human amnesia, delayed retention of object discrimination. However, as described below, when compared to a larger group of normal animals the animals in the PRPH II group exhibited a deficit on day 1 of the task. Finally, on the concurrent discrimination task, the performance of the animals in the PRPH II group was not statistically different from the performance of normal animals. These findings, together with the results obtained previously for the PRPH I group (Zola-Morgan et al., 1989c), arc discussed below.

\section{Delayed nonmatching to sample}

The PRPH II group, like the PRPH I group, exhibited a severe memory impairment on the visual version of the DNMS task. Because the PRPH I group was tested only in the visual modality, it could not be determined if their memory deficit extended to modalities other than vision. The finding that the PRPH II group exhibited deficits on both the visual version of the DNMS task, and on the tactual version of the DNMS task, indicated that the perirhinal and parahippocampal cortices are scrving a more global role in memory function, and not contributing specifically to visual memory. The finding of a memory impairment in both the visual and the tactual modalities is consistent with previous findings showing that monkeys with damage to the medial temporal lobe $\left(\mathrm{H}^{+} \mathrm{A}^{+}\right.$lesion; Murray and Mishkin, 1984), as well as human amnesic patients (Milner, 1972), also exhibit multimodal memory deficits.

The second major finding was that the PRPH lesion produced a long-lasting memory impairment. When monkcys in the PRPH II group were retested on the visual version of the DNMS task approximately 2 years after surgery, they relearned the basic task as rapidly as normal animals. Nevertheless, the PRPH II group continued to exhibit a significant impairment on the delay portion of the task. These results make two points. First, although the perirhinal and parahippocampal cortices contributed to the ability to learn the DNMS task the first time it was encountered, once the task was learned the perirhinal and parahippocampal cortices were no longer necessary to retain the nonmatching rule or to retain information across an $8 \mathrm{sec}$ delay interval. Second, the perirhinal and parahippocampal cortices are critically important for the ability to remember information across delay intervals longer than $8 \mathrm{sec}$ and this ability did not recover with time. The finding of a long-lasting memory impairment in animals with PRPH lesions is consistent with previous findings in monkeys with medial temporal lobe damage (Zola-Morgan et al., 1989a) and human amnesic patients (Milner et al., 1968) who exhibit long-lasting memory impairments.

Finally, it is useful to compare the performance of monkeys with PRPH lesions and monkeys with $\mathrm{H}^{+} \mathrm{A}+$ lesions on the first administration of the DNMS task. The $\mathrm{H}^{+} \mathbf{A}^{+}$lesion includes damage to the hippocampal formation, parahippocampal cortex, amygdala, and unintended damage to the perirhinal cortex. The memory deficit associated with the $\mathrm{H}^{+} \mathrm{A}^{+}$lesion in monkeys has been well studied and resembles human amnesia in many ways (Mishkin, 1978; Zola-Morgan and Squire, 1990; Squire and Zola-Morgan, 1991).

On the learning component of the task (basic task with an 8

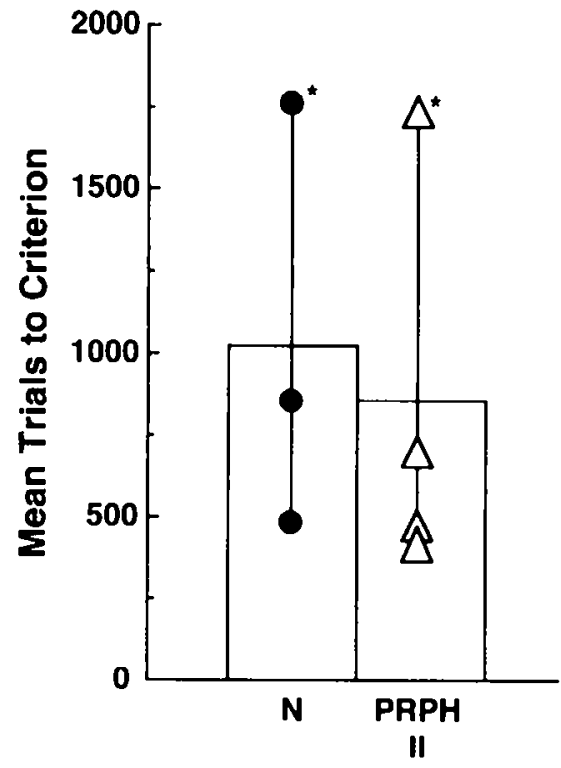

Figure 10. Performance on the eight-pair concurrent discrimination task by normal monkeys $(N)$ and monkeys with lesions of the perirhinal and parahippocampal cortices (PRPH II). Symbols show scores for individual monkeys (see Table 2). Asterisks indicate animals that did not reach criterion level performance (see Behavioral results for details).

sec delay), the monkeys in the PRPH I group, the PRPH II group, and the $\mathrm{H}^{+} \mathrm{A}$ ' group were tested using different methods. The animals in our $\mathrm{H}^{+} \mathrm{A}^{+}$group received single sample presentation throughout testing (Zola-Morgan and Squire, 1985). The animals in the PRPH I group received single sample presentation for the first 1000 trials of testing. If they had not learned the task at this point, they then received double-sample presentation for all remaining trials. The four animals in the PRPH II group received double-sample presentation from the start of testing. Despite the putative benefit of the double-sample presentation procedure on learning, the animals with PRPH lesions performed consistently worse than the animals with $\mathrm{H}^{+} \mathrm{A}^{+}$ lesions [mean trials to criterion: PRPH I and PRPH II $(N=8)$, 1426; $\left.\mathrm{H}^{+} \mathrm{A}^{+}(N=4), 790 ; P<0.05\right]$. One possible explanation for this finding could lie in the fact that the animals in the PRPH groups consistently sustaincd more damage to the lateral aspect of the ventrally situated perirhinal cortex than did the animals in the $\mathrm{H}^{+} \mathrm{A}^{+}$group (Zola-Morgan et al., 1989c). There are at least two ways that greater damage of the perirhinal cortex could have contributed to the observed deficit. More extensive perirhinal damage could have exacerbated the memory impairment of the PRPH groups relative to the $\mathrm{H}^{+} \mathrm{A}^{+}$group, or it could have produced a more severe deficit in rule leaming or some other general cognitive function. The present study cannot distinguish between these two possibilities.

On the delay component of the DNMS task, the PRPH groups and the $\mathrm{H}^{+} \mathrm{A}^{+}$group were also tested using different procedures. The four animals in the $\mathrm{H}^{+} \mathrm{A}^{+}$group and one of the animals in the PRPH I group received single sample presentation on the delays. The remaining four animals with PRPH lesions that were tested on the delay portion of the task all received doublesample presentation. In contrast to their performance on the learning component of the task, the animals in the PRPH groups performed better than the animals in the $\mathrm{H}^{+} \mathrm{A}^{+}$group on the delay component of the DNMS task [mean of the $15 \mathrm{sec}, 60$ sec, and 10 min delays: PRPH I and II $(N=5), 71 \% ; \mathrm{H}^{+} \mathbf{A}^{+}(N$ 
$=4), 61 \% ; P<0.05$ ]. However, because of the difference in testing procedure, it is not clear whether the PRPH groups performed better than the $\mathrm{H}^{+} \mathrm{A}+$ group because their memory impairment was less severe, or because the double-sample presentation procedure facilitated their performance on delays relative to what their performance would have been had they been tested using the single-sample presentation procedure. Recently acquired data speak to this issue. Animals with damage to the perirhinal cortex, parahippocampal cortex, and hippocampal formation ( $\mathrm{H}^{++}$group) exhibited a level of impairment that was sinilar to the animals in the PRPH groups on both the learning component of the DNMS task (first administration) as well as on the delay portion of the task [mean trials to criterion: PRPH I and II $(N=8), 1426 ; \mathrm{H}^{++}(N=4), 1098$; mean of three delays: PRPH I and II $(N=5), 71 \% ; \mathrm{H}^{++}(N=4), 73 \%$; Zola-Morgan et al., 1993]. Importantly, three of the four animals in the $\mathrm{H}^{++}$ group were tested using the single-sample presentation procedure on the delay portion of the task [mean of three delays for $\mathrm{H}^{++}(N=3), 74 \%$ ]. Thus, the findings from the $\mathrm{H}^{++}$group suggest that the use of the double-sample presentation procedure may not underlie the better performance of the PRPH groups relative to the $\mathrm{H}^{+} \mathrm{A}^{+}$group on delays. Another possible explanation for these findings is that the $\mathrm{H}^{+} \mathrm{A}^{+}$group sustained more direct damage to the unimodal visual areas TE and TEO as well as to the white matter lateral to the amygdala than did the animals in the PRPH groups (Zola-Morgan et al., 1989c) or the animals in the $\mathrm{H}^{++}$group (Zola-Morgan et al., 1993). This white matter lateral to the amygdala carrics, among other things, at least some of the afferent and efferent fibers of the perirhinal cortex (Murray, 1992) and area TE.

In a previous study we suggested that the PRPH I group was as impaired or more impaired than the $\mathrm{H}^{+} \mathrm{A}^{+}$group on the delay component of the DNMS task. In that study, two of the animals in the PRPH I group performed even worse than the animals in the $\mathrm{H}^{+} \mathrm{A}^{+}$group on the $8 \mathrm{sec}, 15 \mathrm{sec}$, and $60 \mathrm{sec}$ delays when probe trials of single sample presentation were given (Zola-Morgan et al., 1989c). However, only a small number of probe trials were given for each delay (10-20 trials per delay). Therefore, it is unclear whether these PRPH I animals performed more poorly on the probe trials than on the doublesample presentation trials because of their memory impairment, or because they approached the probe trials as a novel task.

\section{Delayed retention of object discrimination and concurrent discrimination}

Whereas both the PRPH I and PRPH II groups exhibited a severe deficit on the visual version of the DNMS task, on two other tasks sensitive to human amnesia, the performance of the two PRPH groups differed. On the delayed retention of object discrimination task, the PRPH I group exhibited a significant overall impairment (Zola-Morgan et al., 1989c). In contrast, the performance of the PRPH II group did not differ significantly from the $\mathbf{N}$ group on day 1 , day 2 , or day 4 . It should be noted, however, that the performance of two of the PRPH Il animals on day 1 of the task was not only outside the range of scores for the $\mathrm{N}$ group (performance on day 1: PRPH 7, 55\% correct; PRPH 8, 62\% correct; range for the three normal monkeys, 65$73 \%$ correct), but also outside the range of scores for 10 additional normal animals tested previously in our laboratory (range of scores for 10 normal monkeys on day 1, 70-78\% correct; Zola-Morgan and Squire, 1985; Zola-Morgan et al., 1992). Indeed, on day 1 , the PRPH II group as a whole performed significantly worse than the combined group of 13 normal animals $(P<0.05)$. Thus, whereas both the PRPH I and PRPH II groups exhibited an impairment on day 1 of this task, the PRPH I group continued to exhibit a significant deficit on days 2 and 4 of the task, while the performance scores of the PRPH II group on days 2 and 4 did not differ significantly from the scores of normal animals.

Similarly, on the concurrent discrimination task, the two animals in the PRPH 1 group that were tested on this task never reached critcrion level performance within 1200 trials of testing (average percentage correct during the final two sessions, 72\% and $53 \%$ ). In contrast, three of the four animals in the PRPH II group performed within the range of normal animals. The remaining animal (PRPH 8 ) exhibited a severe deficit, never reaching criterion after 1840 trials (average percentage correct during the final two sessions, 68\%). This animal also did not learn either the visual or the tactual versions of the DNMS task and was found to have a preexisting unilateral lesion of area $7 \mathrm{a}$ of the parictal cortex. (It should also be noted that animal N3 did not reach criterion performance on the concurrent discrimination task, averaging $79 \%$ correct during the last two sessions when testing was discontinued after 1760 trials. This score can probably be considered anomalous because in our experience with 10 previously tested normal animals, no other animal has ever failed to learn this task.) In summary, on both the delayed retention of object discrimination task and the concurrent discrimination task, the performance of the PRPI II group appears to be better than that of the PRPH I group.

There are at least two possible explanations for these inconsistent results. One possibility is that the animals in the PRPH II group were able to perform well on these tasks because they approached the tasks as tasks of habit memory or nondeclarative memory. This kind of memory does not require the integrity of the medial temporal lobe (Mishkin and Petri, 1984; Squire and Zola-Morgan, 1991). Other groups have shown in both the rat (Eichenbaum et al., 1989, 1990) and the monkey (Saunders and Weiskrant7, 1989) that tasks may be solved using more than one strategy. Another possible explanation is based on detailed histological analyses of the brains of the animals in the PRPH I and PRPH II groups. This analysis revealed that one subtle though consistent difference in the lesion between the two groups was that the animals in the PRPH I group sustained some direct damage to the CA1-subicular border area, whereas the animals of the PRPH II group had little if any direct damage to this region (see Histological results). Importantly, neuroanatomical data indicated that there was at least some remaining cortical input to the rostral entorhinal cortex, in particular from the spared temporal polar region of the perirhinal cortex, in both the PRPH I and PRPH II groups. Taken together, these neuroanatomical and histological data raised the possibility that the hippocampus of the animals in the PRPH II group had access to some cortical sensory information that may have been sufficient to support performance on the two discrimination tasks. In contrast, the damage to the alveus and cells of the CAlsubicular border region in the animals of the PRPH I group may have disrupted the processing of this residual sensory information through the hippocampus. The idea that the addition of dircet hippocampal damage to a PRPH lesion can produce a more severe deficit on the delayed retention of object discrimination task and concurrent task is consistent with the idea that as more of the medial temporal lobe memory system is damaged, the memory impairment can become more severe (Zola- 
Morgan et al., 1993). It should be noted that, whereas this putative corticohippocampal route in the PRPH II group may have been sufficient to sustain performance on the two discrimination tasks described above, it was not sufficient to sustain or even noticeably improve the performance of the PRPH II group on the DNMS task compared to the PRPH I group.

\section{Neuroanatomical considerations}

In attempting to understand the role of the perirhinal and parahippocampal cortices in memory function, it is important to consider the unique pattern of anatomical connections of these areas. In general, the connections of the perirhinal and parahippocampal cortices provide an interface for information flow between much of the neocortical mantle and the hippocampal formation. The perirhinal and parahippocampal cortices receive inputs from a variety of unimodal and polymodal association cortices. Whereas the perirhinal cortex receives strong inputs from unimodal visual areas in the inferotemporal cortex (Webster et al., 1991) and the ventral bank of the superior temporal sulcus, the parahippocampal cortex receives its major inputs from polymodal associational areas in the dorsal bank of the superior temporal sulcus, retrosplenial cortex, and area 7 of parietal cortex, and relatively little direct input from unimodal visual areas (Suzuki and Amaral, 1990). In addition, auditory association areas in the superior temporal gyrus are reciprocally interconnected with the parahippocampal cortex (Tranel et al., 1988; Suzuki and Amaral, unpublished observations). Finally, putative somatosensory associational areas in the insula project both to the perirhinal cortex (Mesulam and Mufson, 1982; Freedman et al., 1986) and to the parahippocampal cortex (Suzuki and Amaral, unpublished observations).

The perirhinal and parahippocampal cortices, in turn, are the major source of cortical input to the monkey entorhinal cortex, providing approximately $60 \%$ of its direct cortical input (Insausti et al., 1987). The entorhinal cortex then conveys this sensory information to the other areas of the hippocampal formation via the perforant path (Witter and Amaral, 1991). The perirhinal and parahippocampal cortices are also a major recipient of the feedback projections from the hippocampal formation to the neocortex. They receive a prominent projection from the entorhinal cortex and project, in turn, to the same cortical areas from which they receive inputs. Thus, the perirhinal and parahippocampal cortices convey information bidirectionally between high-order sensory associational arcas and the hippocampal formation.

Based on the anatomy of this system alone, it cannot be determined whether the perirhinal and parahippocampal cortices simply relay sensory information to the hippocampal formation or contribute directly to memory function. However, previous data from our laboratory provide evidence that the perirhinal cortex contributes directly to memory function. For example, it has recently been shown that animals with bilateral damage to the hippocampal formation, parahippocampal cortex, as well as the perirhinal cortex ( $\mathrm{H}^{++}$lesioned group) exhibit a more severe memory deficit than monkeys with $\mathrm{H}^{+}$lesions (Squire and Zola-Morgan, 1991; Zola-Morgan et al., 1992b). Thus, the additional involvement of the perirhinal cortex in the $\mathrm{H}^{++}$lesion, but not in the $\mathrm{H}^{+}$lesion, may contribute substantially to the more severe memory deficit exhibited by the $\mathrm{H}^{++}$ group (see also Squire and Zola-Morgan. 1991, and Zola-Morgan et al., 1993, for further discussion of this point). Thus, these studies are consistent with the idea that the perirhinal cortex itself contributes directly to memory function.

The conclusion that the perirhinal cortex plays an essential role in memory function is consistent with results from other studics as well. In a behavioral study of monkeys with ablations of the antcroventral temporal cortex, the animal most impaired on a delayed match to sample task sustained a lesion involving mainly the perirhinal cortex (Horel et al., 1987). Similarly, animals with lesions of the perirhinal cortex, entorhinal cortex, and amygdala exhibited a more severe deficit than animals with $\mathrm{H}^{+}$lcsions (Murray and Mishkin, 1986; see also Murray, 1992). More recently, it has been reported that bilateral lesions limited to the perirhinal cortex produced a substantial impairment in visual recognition memory compared to control animals (Meunier et al., 1990). Finally, the findings in both rodents (Otto and Eickenbaum, 1992) and monkeys (Graffan and Murray, 1992) that combined lesions of the entorhinal and perirhinal cortex produce a severe memory impairment are also consistent with the idea that the perirhinal cortex contributes to memory function.

There is also a growing body of data concerning the electrophysiological properties of cells in ventral inferotemporal cortex of awake monkeys during the performance of visual memory tasks. One study showed that cells presumably located in and around the perirhinal cortex exhibited sustained activity during the $16 \mathrm{sec}$ delay interval of a delayed match to sample task (Miyashita and Chang, 1988). Using slightly different versions of the delayed match to sample task, others have reported that cells in this region responded significantly less to a visual stimulus the second time it was presented (Miller et al., 1991; Riches ct al., 1991). Although more work is needed to understand how these findings relate to memory function, it is clear that cells in the region of the perirhinal cortex exhibit memory-related response properties. Overall, both behavioral and electrophysiological evidence suggests that the perirhinal cortex has an important role in visual recognition memory.

Given the anatomical evidence for strong visual inputs to the perirhinal cortex, it is not surprising that this area contributes to visual recognition memory. The unique contribution of the parahippocampal cortex, however, has not becn as thoroughly investigated. The available anatomical information suggests that it may play a different role from the perirhinal cortex. In particular, the parahippocampal cortex, unlike the pcrirhinal cortex, receives strong inputs from area 7 of the parietal cortex (Seltzer and Pandya, 1976). Accordingly, this suggests that the parahippocampal cortex may be involved in the processing of spatial information. Consistent with this idea is the finding that monkeys with lesions involving the parahippocampal cortex, hippocampus, and posterior entorhinal cortex exhibited a more severe spatial memory deficit than monkeys with lesions involving the rostral perirhinal cortex, rostral entorhinal cortex, and amygdala (Parkinson et al., 1988). It will be important to evaluate these ideas directly by testing the effects of selective perirhinal or parahippocampal cortical lesions on both visual and spatial memory tasks.

In summary, the present findings, together with recent neuroanatomical studies examining the connectivity of the perirhinal and parahippocampal cortices, emphasize the importance of these cortical areas for normal memory function. Damage to the perirhinal and parahippocampal cortices in monkeys produced a memory deficit in both the visual and tactual modalities that was long-lasting. Multimodal and enduring memory im- 
pairments are defining characteristics of human amnesia. Anatomical studies have shown that the perirhinal and parahippocampal cortices not only have strong and reciprocal connections with the hippocampal formation but also have strong and reciprocal connections with a wide variety of unimodal and polymodal associational areas in the frontal, parietal, and temporal lobes. In this way, the perirhinal and parahippocampal cortices form an anatomical interface between the hippocampal formation and the rest of the neocortex. Thus, the present findings, together with previous findings emphasizing the importance of the hippocampal formation in memory function (ZolaMorgan et al., 1989a), suggest that the hippocampal formation and adjacent perirhinal and parahippocampal cortices comprise the major components of the medial temporal lobe memory system.

\section{References}

Aggleton JP, Mishkin M (1983) Visual recognition impairment following medial thalamic lesions in monkeys. Neuropsychologia 21: $187-197$.

Alvarez-Royo P, Clower RP, Zola-Morgan S, Squire LR (1991) Stereotaxic lesions of the hippocampus in monkeys: determination of surgical coordinates and analysis of lesions using magnetic resonance imaging. J Neurosci Methods 38:223-232.

Amaral DG, Insausti R, Cowan WM (1987) The entorhinal cortex of the monkey. I. Cytoarchitectonic organization. J Comp Neurol 264: 326-355.

Brodmann K (1909) Vergleichende Lokalisationslehre der Grosshimrinde. Leipzig: Barth.

Eichenbaum H, Mathews P, Cohen NJ (1989) Further studies of hippocampal representation during odor discrimination learning. Behav Neurosci 103:1207-1216.

Eichenbaum H, Stewart C, Morris RGM (1990) Hippocampal representation in place learning. J. Neurosci 10:3531-3542.

Freedman DP, Murray EA, O'Neill JB, Mishkin M (1986) Cortical connections of the somatosensory fields of the lateral sulcus of macaques: evidence for a corticolimbic pathway for touch. J Comp Neurol 252:323-347.

Gaffan D, Murray EA (1992) Monkeys (Macaca fascicularis) with rhinal cortex ablations succeed in object discrimination learning despite 24-hour intertrial intervals and fail at matching to sample despite double sample presentation. Behav Neurosci 106:30-38.

Gellerman LW (1933) Chance orders of alternating stimuli in visual discrimination experiments. J Genet Psychol 42:206-208.

Harlow HF, Bromer JA (1938) A test apparatus for monkeys. Psychol Rec 2:434-438.

Horel JA, Pytko-Joiner DE, Voytko ML, Salsbury K (1987) The performance of visual tasks while segments of the inferotemporal cortex are suppressed by cold. Behav Brain Res 23:29-42.

Insausti R, Amaral DG, Cowan WM (1987) The entorhinal cortex of the monkey. II. Cortical afferents. J Comp Neurol 264:356-395.

Mahut H, Zola-Morgan S, Moss M (1982) Hippocampal resections impair associative learning and recognition memory in the monkey. J Neurosci 2:1214-1229.

Malamut BL, Saunders RC, Mishkin M (1984) Monkeys with combined amygdalo-hippocampal lesions succeed in object discrimination learning despite 24-hour intertrial intervals. Behav Neurosci 98: 759-769.

Mesulam MM, Mufson EJ (1982) Insula of the old word monkey. III: Efferent cortical output and comments on function. J Comp Neurol 212:38-52.

Meunier M, Murray EA, Bachevalier J, Mishkin M (1990) Effects of perirhinal cortical lesions on visual recognition memory in rhesus monkeys. Soc Neurosci Abstr 16:616.

Miller EK, Lin L, Desimone R (1991) A neural mechanism for working and recognition memory in inferior temporal cortex. Science 254: $1377-1379$.

Milner B (1972) Disorders of learning and memory after temporal lobe lesions in man. Clin Neurosurg 19:421-446.

Milner B, Corkin S, Teuber HL (1968) Further analysis of the hip- pocampal amnesic syndrome: 14 year follow-up study of H.M. Neuropsychologia 6:215-234.

Mishkin M (1978) Memory in monkeys severely impaired by combined but not separate removal of the amygdala and hippocampus. Nature 273:297-298.

Mishkin M, Petri HL (1984) Memories and habits: some implications for the analysis of learning and retention. In: The neuropsychology of memory (Butters N, Squire LR, eds), pp 287-296. New York: Guilford.

Miyashita Y, Chang HS (1988) Neuronal correlate of pictorial shortterm memory in the primate temporal cortex. Nature 331:68-70.

Murray EA (1992) Medial temporal lobe structures contributing to recognition memory: the amygdaloid complex versus the rhinal cortex. In: The amygdala (Aggleton JP, ed), pp 453-470. London: WileyLiss.

Murray EA, Mishkin M (1984) Severe tactual as well as visual memory deficits follow combined removal of the amygdala and hippocampus in monkeys. J Neurosci 4:2565-2580.

Murray EA, Mishkin M (1986) Visual recognition in monkeys following rhinal cortical ablations combined with either amygdalectomy or hippocampectomy. J Neurosci 6:1991-2003.

Otto T, Eickenbaum H (1992) Complimentary roles of the orbital prefrontal cortex and the perirhinal-entorhinal cortices in an odorguided delayed-nonmatching-to-sample task. Behav Neurosci 106: 763-776.

Overman WH, Ormsby G, Mishkin M (1990) Picture recognition vs. picture discrimination learning in monkeys with medial temporal removals. Exp Brain Res 79:18-24.

Parkinson JK, Murray EA, Mishkin M (1988) A selective mnemonic role for the hippocampus in monkeys: memory for the location of objects. J Neurosci 8:4159-4167.

Riches IP, Wilson FAW, Brown MW (1991) The effects of visual stimulation and memory on neurons of the hippocampal formation and the neighboring parahippocampal gyrus and inferior temporal cortex of the primate. I Neurosci 11:1763-1779.

Saunders RC, Weiskrantz L (1989) The effects of fornix transection and combined fornix transection, mammillary body lesions and hippocampal ablations on object-pair association memory in the rhesus monkey. Behav Brain Res 35:85-94.

Scoville WB, Milner B (1957) Loss of recent memory after bilateral hippocampal lesions. J Neurol Neurosurg Psychiatry 20:11-21.

Seltzer B, Pandya DN (1976) Some cortical projections to the parahippocampal area in the rhesus monkey. Exp Neurol 50:146-160.

Squire LR (1992) Memory and the hippocampus: a synthesis from findings with rats, monkeys, and humans. Psychol Rev 99:195-231.

Squire LR, Zola-Morgan S (1991) The medial temporal lobe memory system. Science 253:1380-1386.

Squire LR, Zola-Morgan S, Chen K (1988) Human amnesia and animal models of amnesia: performance of amnesic patients on tests designed for the monkey. Behav Neurosci 102:210-221.

Squire LR, Amaral DG, Press GA (1990) Magnetic resonance imaging of the hippocampal formation and mammillary nuclei distinguish medial temporal lobe and diencephalic amnesia. J Neurosci 10:31063117.

Suzuki WA, Amaral DG (1990) The organization of cortical inputs to the perirhinal (areas 35 and 36) and parahippocampal (areas TH and TF) cortices in the monkey. Soc Neurosci Abstr 16:53.

Szabo J, Cowan WM (1984) A stereotaxic atlas of the brain of the cynomolgus monkey (Macaca fascicularis). J Comp Neurol 222:265300.

Trancl D, Brady DR, Van Hoesen GW, Damasio AR (1988) Parahippocampal projections to posterior auditory association cortex (area Tpt) in old-world monkeys. Exp Brain Res 70:406-416.

Van Essen DC, Maunsell JHR (1980) Two-dimensional maps of the cerebral cortex. J Comp Neurol 191:225-281.

Victor M, Agamanolis D (1990) Amnesia due to lesions confined to the hippocampus: a clinical-pathologic study. J Cognit Neurosci 2:246257.

von Bonin G, Bailcy P (1947) The neocortex of Macaca mulatta. Urbana, IL: University of Illinois.

Webster MJ, Ungerleider LG, Bachevalier J (1991) Connections of inferior temporal areas TE and TEO with medial temporal-lobe structures in infant and adult monkeys. J Neurosci 11:1095-1116.

Witter MP, Amaral DG (1991) Entorhinal cortex of the monkey. V. 
Projections to the dentate gyrus, hippocampus, and subicular complex. J Comp Neurol 307:437-459.

Zeki SM (1971) Cortical projections from two prestriate areas in the monkey. Brain Res 34:19-35.

Zola-Morgan S, Squire LR (1984) Preserved learning in monkeys with medial temporal lesions: sparing of cognitive skills. J Neurosci 4:10721085 .

Zola-Morgan S, Squire LR (1985) Medial temporal lesions in monkeys impair memory in a variety of tasks sensitive to human amnesia. Behav Neurosci 99:22-34

Zola-Morgan S, Squire LR (1986) Memory impairment in monkeys following lesions of the hippocampus. Behav Neurosci 100:165-170.

Zola-Morgan S, Squire LR (1990) Identification of the memory system damaged in medial temporal lobe amnesia. In: The biology of memory (Squire LR, Lindenlaub E, eds), pp 509-521. Stuttgart: Schautter.

Zola-Morgan S, Squire LR, Amaral DG (1986) Human amnesia and the medial temporal region: enduring memory impairment following a bilateral lesion limited to ficld CAl of the hippocampus. J Neurosci 6:2950-2967.
Zola-Morgan S, Squire LR, Amaral DG (1989a) Lesions of the hippocampal formation but not lesions of the fornix or the mammillary nuclei produce long-lasting memory impairment in monkeys. J Neurosci 9:897-912.

Zola-Morgan S, Squire LR, Amaral DG (1989b) Lesions of the amygdala that spare adjacent cortical regions do not impair memory or exacerbate the impairment following lesions of the hippocampal formation. J Neurosci 9:1922-1936.

Zola-Morgan S, Squire LR, Amaral DG, Suzuki WA (1989c) Lesions of perirhinal and parahippocampal cortex that spare the amygdala and hippocampal formation produce severe memory impairment. J Neurosci 9:4355-4370.

Zola-Morgan S, Squire LR, Rempel NL, Clower RP, Amaral DG (1992) Enduring memory impairment in monkeys after ischemic damage to the hippocampus. J Neurosci, 9:4355-4370.

Zola-Morgan S, Squire LR, Clower RP, Rempel NL (1993) Damage to the perirhinal cortex but not the amygdala exacerbates memory impairment following lesions to the hippocampal formation. J Neurosci 12:2582-2596. 